\title{
A Model of Surface Residual Stress Distribution of Cold Rolling Spline
}

\author{
Z. H. Ding, ${ }^{1,2}$ F. K. Cui, ${ }^{1,2}$ Y. B. Liu, ${ }^{1,2}$ Y. Li, ${ }^{3}$ and K. G. Xie ${ }^{1,2}$ \\ ${ }^{1}$ School of Mechatronics Engineering, Henan University of Science and Technology, Henan, China \\ ${ }^{2}$ Collaborative Innovation Center of Machinery Equipment Advanced Manufacturing of Henan Province, Luoyang 471003, China \\ ${ }^{3}$ School of Mechanical and Precision Instrument Engineering, Xi'an University of Technology, Xian 710048, China \\ Correspondence should be addressed to Z.H. Ding; 649373120@qq.com
}

Received 17 April 2017; Revised 19 June 2017; Accepted 11 July 2017; Published 5 September 2017

Academic Editor: Edoardo Artioli

Copyright (C) 2017 Z. H. Ding et al. This is an open access article distributed under the Creative Commons Attribution License, which permits unrestricted use, distribution, and reproduction in any medium, provided the original work is properly cited.

\begin{abstract}
Residual stress is an important parameter in the evaluation of the performance of a cold rolling spline surface. However, research on cold rolling spline is rare. To improve the surface property of a spline, an involute spline is selected as the object of this study. The contour method for determining cold roll-beating residual stress involves measuring the force spatial distribution, performing a statistical analysis of the experimental results, establishing the parameters for the tooth profile for different positions (dedendum, pitch, and addendum) of residual stress, and determining the effect of pressure on the relationship between stress and the depth of the cold roll-beating. A response surface method is used to establish the spline tooth profile of the dedendum, pitch, and addendum of the residual stress and different depths of the stress layer to obtain the parameters of a multiple regression model and perform a comparative analysis of the experimental and prediction results. Research indicates that the prediction results have high reliability. The establishment of this model has important guiding significance to control the residual stress in the cold roll-beating forming process, optimize the cold roll-beating processing parameters, and improve the surface properties of cold rolling spline.
\end{abstract}

\section{Introduction}

Cold roll-beating technology is a new type of chipless nearnet forming technology that enables environmental protection and energy savings with high efficiency, a high material utilization rate, and an extensive application value in the automobile industry and the aerospace sector and for major strategic equipment manufacturing processes. High-speed cold roll forming is a progressive forming process during nonuniform thermal mechanical coupling. The forming process of a workpiece surface will inevitably produce residual stress. Residual stress can reduce the surface microcrack expansion of a workpiece and increase its fatigue strength, which will affect the stability of the workpiece size [1-5]. Residual stress is an important parameter for the surface performance of a workpiece, and its type and peak size and depth of the working layer are important factors that affect the surface properties of cold-rolled workpieces. However, various questions arise during the actual production process. How do different cold roll-beating process parameters affect the workpiece residual stress state and its distribution? What method can be employed to predict the surface residual stress of a cold roll-beating workpiece when setting the cold rolling process parameters? What method can be employed to optimize the cold roll-beating process parameters according to the stress state of the workpiece application? Research on the spatial distribution and prediction model of the residual stresses in cold roll-beating during nonuniform thermal mechanical coupling is necessary. Providing accurate control of residual stress during cold roll-beating and optimization of the cold roll-beating processing parameters improve the surface performance of cold roll-beating workpiece forming and have theoretical significance and high engineering application value.

In recent years, domestic scientists have investigated the cold roll-beating plastic forming process using modern numerical simulation. Cui [6] employed a rigid plastic numerical simulation method for a cold rolling forming spline shaft finite element analysis and provided a preliminary description of the cold roll-beating process. The spline shaft 
in the forming process was determined to be prone to collapse in front of defects, and the causes for collapse were determined from an angle of deformation force analysis of mechanics. Cui [7] analyzed the high-speed cold roll-beating of an involute spline by studying the relationship between cold roll-beating and workpiece forming motion using a mathematical model of the forming process of the dynamic response and stress wave. The cold roll-beating process of metal flow law and deformation mechanism were determined from a macro perspective. Quan et al. [8] employed an explicit central difference algorithm and the finite element software ANSYS/LS-DYNA; the numerical simulation of an involute spline shaft's cold rolling forming was realized according to the calculated results. The metal flowing law, the von Mises stress, and the formed outer diameter of an involute spline were forecasted; the errors between the simulation results and the dentiform object of the involute spline were analyzed. Cui et al. [9-11] employed a forming method to design and manufacture rollers without an inaccurate outline and constructed a math model of rollers outline design, in which the experimental method was applied to correct the theoretical outline of rollers. They developed a simulation system of rollers, verified the correctness of the design and manufacture of rollers, and performed a series of process experiments of an actual spline shaft, which caused the formation of coldbeating to attain higher machining precision. Li et al. [12] determined the parameters of the Johnson-Cook dynamic constitutive equation for $40 \mathrm{Cr}$ using experimental methods, predicted flow stress based on the constitutive equations, and compared the real stress with the experimental data. Based on the comparisons, the true stress calculated based on the model and the predicted flow stress are both consistent with the experimental data, which conclude that the presented dynamic constitutive model can effectively predict the plastic flow stress for $40 \mathrm{Cr}$ quenched and tempered steel. According to the principle of an involute spline cold roll-beating, Cui et al. [13] established the contact model between the rollers and the spline shaft blank in the process of cold roll-beating forming via FEM simulation. They investigated the formation mechanism of the involute spline tooth profile in the cold roll-beating forming process and analyzed the node flow tracks of the deformation area. Experimental research on the metal flow of a cold roll-beating spline is conducted; the results conclude that the particle flow directions of the deformable bodies in a cold roll-beating deformation area are determined by the minimum moving resistance. Cui and others [14] established a finite element model for cold rollbeating simulation based on the thermal effect in different roller speeds. Based on the simulation results, the change in equivalent stress due to the thermal-mechanical mechanism was analyzed, and its influence on work hardening was determined. Zhang and others [15] amended the analytical equation based on the principal stress method of cold rolling processing deformation force analysis solution via a simulation analysis. In the field of residual stress, Valiorgu et al. [16] developed a new methodology to predict residual stresses induced in the finish turning of an AISI304L stainless steel. Navas et al. [17] measured the surface residual stresses in AISI 4340 steel bars that were subjected to turning tests via
X-ray diffraction using different cutting speeds and cutting feeds and cutting tools with different nose radii and surface states. They determined not only the magnitude but also the orientation of the principal residual stresses. Jiang et al. [18] established a finite element model using elastic-plastic theory and discussed the effect of the original hardness of the workpiece, the geometry of the cutting tool, and the cutting conditions on the spatial distribution of the residual stress on the formed surface. Sun et al. [19] established a threedimensional finite element model of machining and obtained the variation of surface residual stress with the process parameters via the cutting process parameter design. They discussed the impact of first cutting and second cutting on residual stress formation based on the simulation of different processing procedures. They also performed a cutting experiment to verify the accuracy of the finite element simulation. Capello [20] established an empirical relationship between the residual stress and the machining parameters using experimental data. Ulutan et al. [21] established a prediction model of residual stress during thermomechanical coupling based on an analysis of existing models. Lazoglu et al. [22] employed elastic-plastic mechanics theory to establish a prediction model of residual stress based on the consideration of the comprehensive thermal and mechanical effect on the workpiece surface and the stress relaxation problem. Guo [23] employed a numerical simulation method to study the residual stress distribution of different materials. Ding [24] simulated an ultraprecise cutting process, proposed an algorithm that is suitable for measuring the residual stress on the cutting surface, processed the simulation data on the MATLAB platform, and employed a statistical method to establish a model for predicting the residual stress amplitude and depth.

Many scholars have performed considerable research on theoretical models of residual stress, finite element simulations, and residual stress prediction models. Although the forming process, metal flow, and forming mechanism of cold roll-beating have been investigated, few studies have focused on the residual stress in cold roll-beating; in particular, research on the residual stress distribution prediction model of cold roll-beating has not been reported. Therefore, this study investigates the distribution of residual stress with different cold rolling parameters and establishes a prediction model. The results are expected to provide accurate control of the residual stress in the cold-forming process and enable the optimization of the process parameters, which improve the surface properties of the workpiece after the cold roll-beating process.

\section{Experimental Study of the Residual Stress of Cold Roll-Beating of an Involute Spline}

2.1. Experimental Principle. The principle of the experiment to determine the distribution of residual stress on the cold roll-beating workpiece using the contour method for measurement is shown in Figure 1 [25-27]. The presence of an unknown residual stress $\sigma_{x}$ inside the specimen is assumed. As shown in Figure 1(a), the specimen is cut in half along the section to be analyzed and evaluated for the residual stresses. As the residual stress is released, the cutting surface 

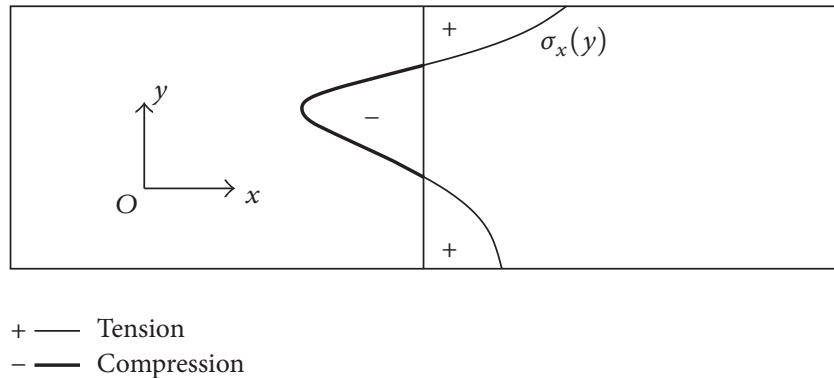

(a)

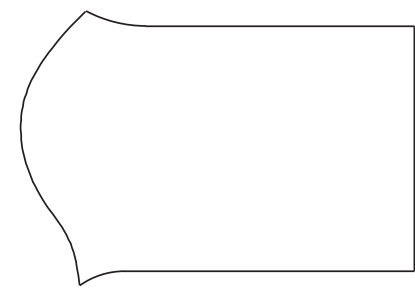

(b)

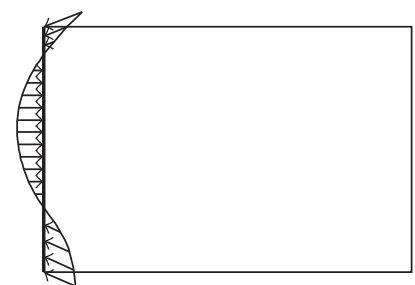

(c)

FIGURE 1: Schematic of the residual stress measurement using the contour method.

contour deforms, as shown in Figure 1(b). According to the superposition principle of elastic-plastic mechanics, if an external force is applied, then the cutting surface recovers to the plane that it occupied before it was cut. The obtained stress state is equivalent to the initial residual stress on the plane prior to cutting, as shown in Figure 1(c).

2.2. Experimental Materials and Parameters. Experiments were performed with the same batch of normalizing grade 20 steel, the main chemical composition of which is shown in Table 1 . The modulus of the cold roll-beating involute spline is 2.5 , the number of teeth is 14 , the pressure angle is $30^{\circ}$, the addendum coefficient is 0.5 , and the dedendum coefficient is 0.75 . The cold roll-beating parameters are as follows: the rotational speeds are $1,428,1,581,1,806,2,032$, and $2,258 \mathrm{r} / \mathrm{min}$, and the feed speeds are $21,28,35$, and $42 \mathrm{~mm} / \mathrm{min}$.

2.3. Experimental Program. In order to obtain the yield limit of grade 20 steel, the compression experiment is adopted in the same material under the same heat treatment process. This is due to the fact that the material compression is the main process in the cold roll-beating process. The sample shape is cylinder, the size is $\Phi 8 \mathrm{~mm} \times 6 \mathrm{~mm}$, and the end faces parallelism of the sample is 0.002 . The sample manufacturing process is as follows: turning, slow feeding linear cutting, grinding, and polishing. The MTS universal testing machine (shown in Figure 2) was used in the grade 20 steel quasi-static compression experiment.

Based on the parameters of the cold roll-beating spline, the material is machined to a cold roll-beating blank. The following process is employed: the rolling wheel rotates clockwise as the workpiece is pulled out. The rolling wheel strikes each tooth one time as the workpiece rotates in a circle. Involute spline processing of different cold rolling forming

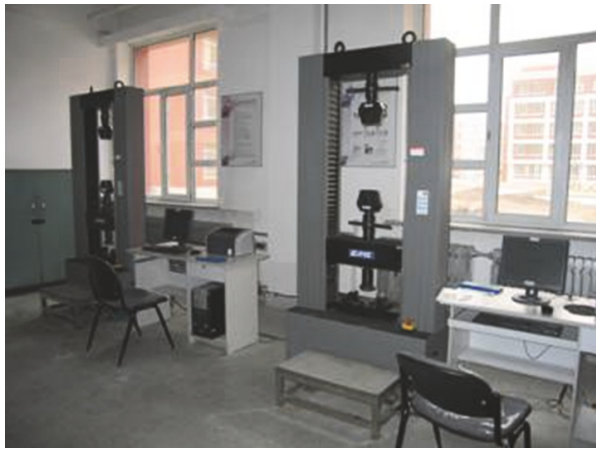

FIGURE 2: MTS universal testing machine.

parameters was performed on a ZRMe9 rolling machine. The spline of cold roll-beating was shown in Figure 3 and the spline sample was shown in Figure 4. In the Serein-CMM type FUNCTION1000 wire cutting machine and using a $0.5 \mathrm{~mm}$ molybdenum wire with a feed speed of $2 \mathrm{~mm} / \mathrm{min}$, a tooth was cut under the cold roll-beating spline; part of the spline tooth was cut along the tooth curve and involved a cutting of the specimen along the symmetrical surface, as shown by the shading in Figure 5, where $l=10 \mathrm{~mm}, w=4.35 \mathrm{~mm}$, and $h=2.68 \mathrm{~mm}$.

One of the sections of the spline tooth specimen is annealed; next, the two samples are bonded by cutting, with the cutting section position (the removed volume should be sufficiently large to ensure that the release of stress can cause a sufficient amount of deformation), as shown in Figure 6.

The point coordinates of the cutting plane of Figure 6 were measured using a Serein-CMM FUNCTION 1000 threecoordinate measuring machine (to reduce the error, both surfaces produced by cutting must be measured, and a total 
TABLE 1: Main chemical composition of grade 20 steel (mass fraction, \%).

\begin{tabular}{lcccccc}
\hline $\mathrm{C}$ & $\mathrm{Si}$ & $\mathrm{Mn}$ & $\mathrm{P}$ & $\mathrm{S}$ & $\mathrm{Ni}$ & $\mathrm{Cr}$ \\
\hline 0.20 & $0.17 \sim 0.37$ & $0.35 \sim 0.65$ & $\leq 0.035$ & $\leq 0.035$ & $\leq 0.30$ & $\leq 0.25$ \\
\hline
\end{tabular}

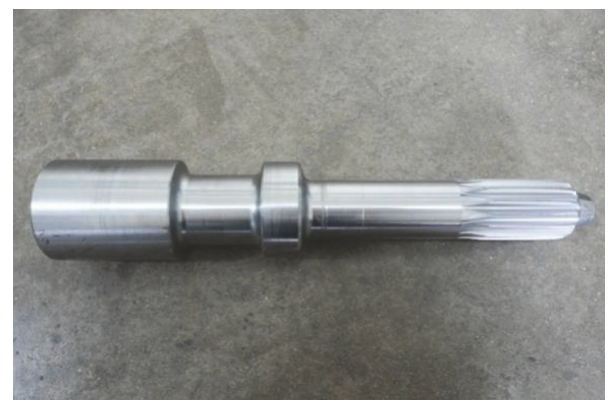

FIGURE 3: Spline of cold roll-beating.

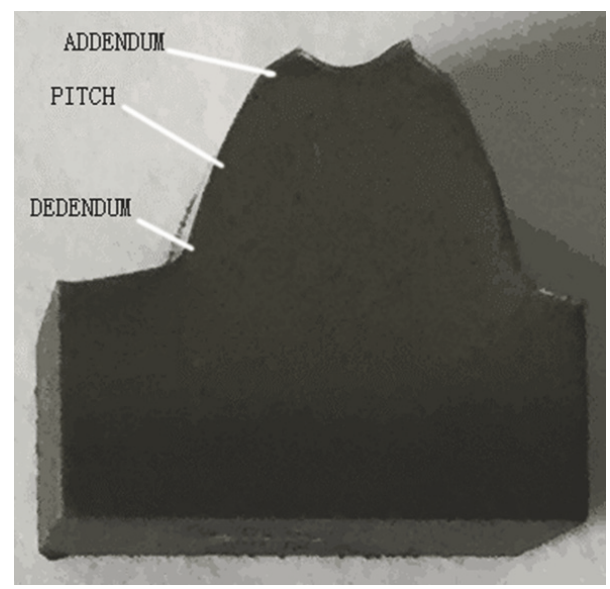

FIGURE 4: Spline sample.

of four surfaces must be measured). The measurement was performed at $0.01 \times 0.01 \mathrm{~mm}$ intervals using the reciprocating measurement method (a single measurement track along the direction parallel to the cutting line is required to cover the two surfaces). The measured data that correspond to the two planes are subtracted to obtain the measured point change amount (vector deformation), which is the amount of deformation caused by the release of the residual stress. A cubic spline curve fitting algorithm is employed to fit the variation (the subtracted data) of each measurement point to a surface. The surface is applied to a finite element model with the same size as the annealed specimen using Abaqus software as a boundary condition. To avoid rigid body displacement during the model analysis, an additional constraint that does not affect the free deformation of the profile is imposed. Next, the finite element calculation is conducted. The stress on the cut surface is equivalent to the residual stress at the same position prior to cutting the sample.

2.4. Experimental Results and Discussion. The stress-strain curve of grade 20 steel quasi-static compression experiment

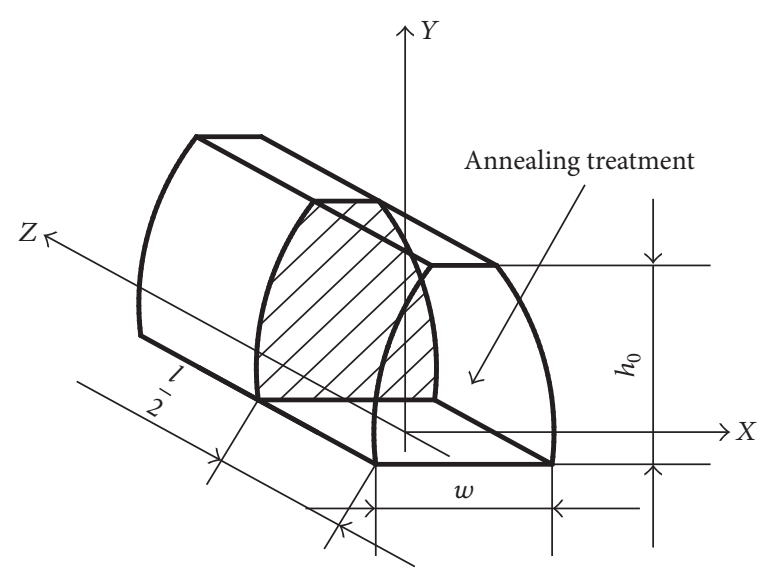

FIGURE 5: Specimen shape and cut position of the measured section.

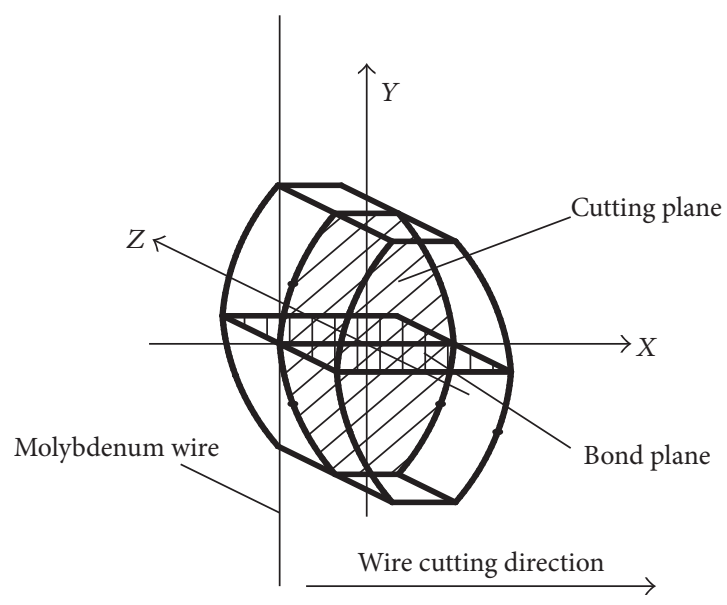

Figure 6: Schematic of the specimen cutting scheme.

is shown in Figure 7. Figure 7 shows that the true stress grows linearly with the increase of true strain reaching the strengthening stage firstly; as the cross-sectional area of the sample increases, the true stress changes slowly as the true strain increases. Grade 20 steel in the compression process has no obvious yield stage, taking $213 \mathrm{MPa}$ as the yield stress which corresponds to the true strain 0.0035 . Because of the plastic deformation of the workpiece and the severe friction between the rolling wheel and the workpiece, the thermal effect is formed during the cold roll-beating process and part of the energy is released in the form of heat; according to the law of conservation of energy, the residual stress is less than $213 \mathrm{MPa}$.

The residual stress curve of the dedendum, pitch, and addendum in three positions in a cold rolling spline with different rotational speeds and different feed rates is shown in Figures 8-12. 


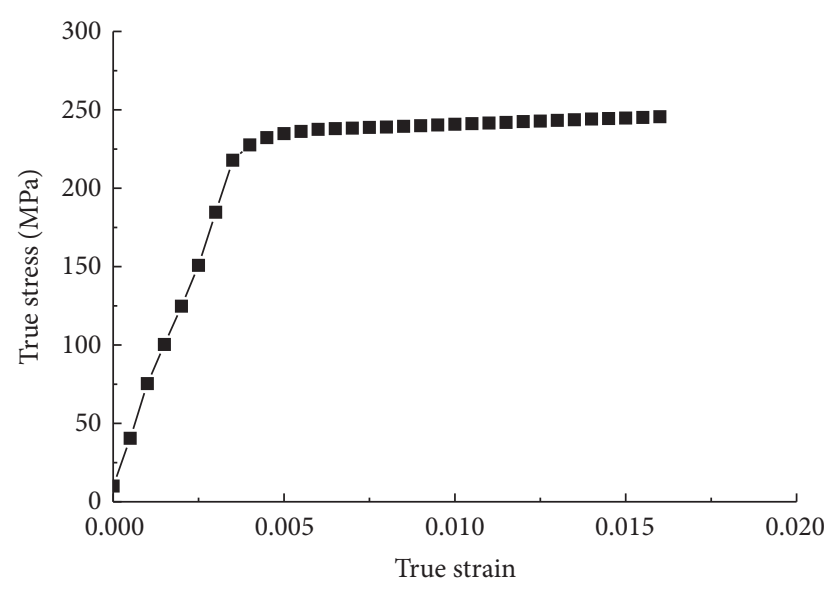

FIGURE 7: True stress-strain curve of grade 20 steel at quasi-static strain rate.

Figures 8-12 show that the tooth superficial coat of the cold rolling spline is composed of the residual compressive stress, and the residual compressive stress on the surface of the tooth superficial coat is small. This is due to the fact that the residual compressive stress of the spline tooth surface has a certain release after cold roll-beating. The residual compressive stress increases with the change in the layer depth; when the layer depth is equal to the depth of the subsurface, the residual compressive stress attains its maximum. The residual compressive stress decreases with an increase in layer depth; when the depth of the layers increases to a certain depth, the residual compressive stress is 0 , and the residual stress changes from compressive stress to tensile stress. The residual tensile stress increases with an increase in layer depth, and the residual tensile stress slowly decreases. The gradient of the residual compressive stress in the subsurface layer is larger than the subsurface layer. After a certain layer depth, the increased gradient of the residual tensile stress is larger than the reduction in residual tensile stress. The variation law of the residual stress with the increase of the depth of the layer with different rotational speeds and different feed rates is consistent. The residual compressive stress in the spline formed at the dedendum is larger than the compressive stress formed at the pitch. The minimum value of the residual compressive stress is attained at the addendum. The deep layer of the residual compressive stress at the spline dedendum is larger than the deep layer at the pitch. The deep layer of residual compressive stress at the addendum is the minimum value.

2.4.1. Experimental Error Analysis. The experimental error of the contour method is caused by fitting error of the spline tooth and cutting plane slightly moving because of stress relief during the wire cutting progress; these errors are difficult to be synthetically calculated and adopt classical residual stress test XRD compared with the contour method.

Proto-LXRD type $\mathrm{X}$ ray stress analyzer was used to test the surface residual stresses of specimens with rotational speed being $1806 \mathrm{r} / \mathrm{min}$ and feed rate being $28 \mathrm{~mm} / \mathrm{min}$. The peeling of the spline teeth is tested by electrolysis corrosion method, and the residual stress in the deep direction of the spline is obtained by layer-by-layer test. The contrast of the residual stress measured by the contour method and the XRD method is shown in Figure 13.

The surface residual stress of the spline tooth profile measured by the contour method is obviously lower than that measured by the XRD method. This is because the fitting error of the spline tooth and the test error are caused by cutting plane slightly moving because of stress relief during the wire cutting progress. Although the contour method has a certain error, the test result still has the same trends as the XRD test result. As is shown in Figure 13, the residual stress magnitude and trend obtained by the two methods are very close to each other. Because of the XRD test, it is difficult to accurately control the delamination depth, and the ProtoLXRD system has the error of fitting diffraction peaks. Therefore, the contour method can be used to test the internal stress with high accuracy.

2.4.2. Variation Rule of the Residual Compressive Stress Peak. The change curve of the peak value of the residual compressive stress with the cold roll-beating rotational speed is shown in Figure 14.

As shown in Figure 14, the peak residual compressive stress of the spline at the dedendum is larger than the peak residual compressive stress at the pitch. The peak residual compressive stress of the addendum is the smallest value. When the rotational speed increased, the peak residual compressive stress curve of the three positions of the tooth profile increases, and the increase of the residual compressive stress of the addendum and the pitch is small. When the feed rate of the cold rolling spline was $21 \mathrm{~mm} / \mathrm{min}$ or $28 \mathrm{~mm} / \mathrm{min}$, the peak value of the residual compressive stress at different rotational speeds at the pitch of spline in cold roll-beating forming ranges from $67.4 \mathrm{MPa}$ to $80.8 \mathrm{MPa}$. The feed rates of the cold roll-beating spline are $35 \mathrm{~mm} / \mathrm{min}$ and $42 \mathrm{~mm} / \mathrm{min}$. The peak value of the residual compressive stress for different rotational speeds at the pitch of the spline in cold roll-beating forming ranges from $79.4 \mathrm{MPa}$ to $86.8 \mathrm{MPa}$. The increase of the residual compressive stress at the dedendum is more significant. Because the nonuniformity of the surface metal flow formation of residual stresses is directly related to the formation of residual stresses during spline cold rolling, the increase in the rotational speed of the cold roll-beating increases the nonuniformity of the flow of the spline surface, and the peak residual stress increases, especially the degree of the metal flow unevenness at the dedendum. The peak residual stress increases, especially the unevenness of the metal flow at the dedendum, and a maximum increase in the peak residual stress is attained. At the same feed rate, the increase in the rotational speed of cold roll-beating causes the amount of striking to be reduced in each round of the workpiece. The effect of thermal mechanical coupling on the formation of residual stress increases, and the peak residual stress has a tendency to decrease. Due to an increase in the rotational speed of the cold roll-beating, the increase of the peak residual stress at the pitch is not significant. Because the forming 


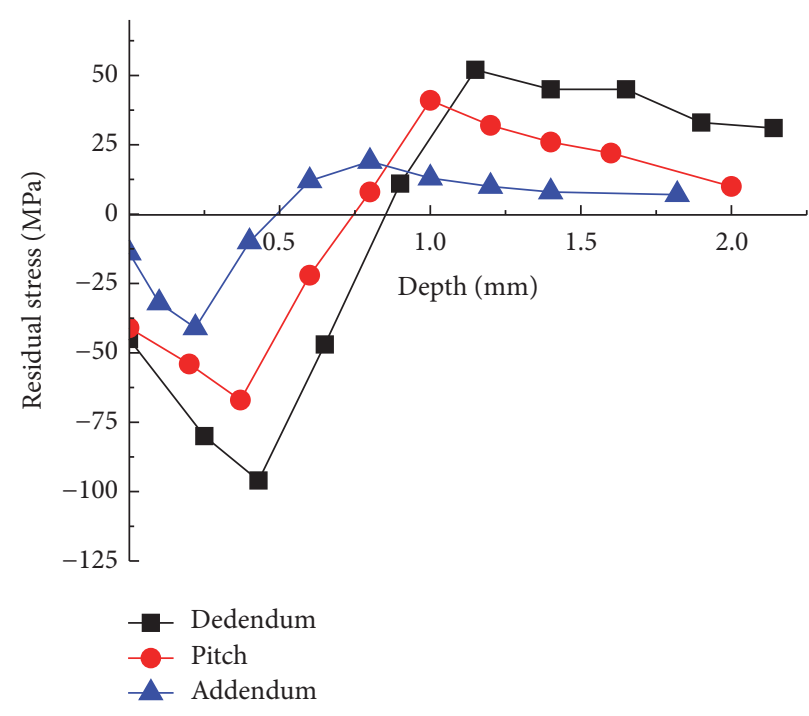

(a) $21 \mathrm{~mm} / \mathrm{min}$

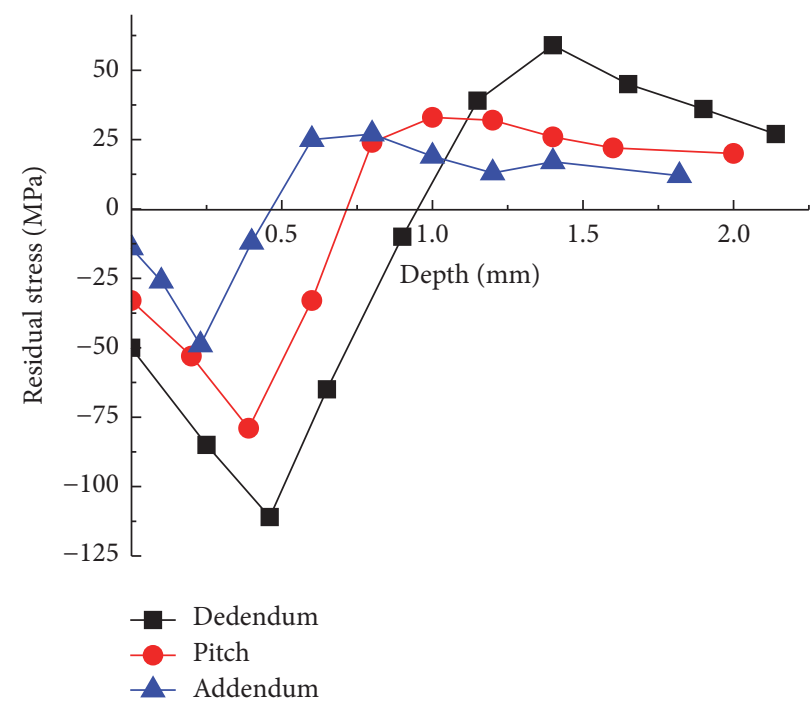

(c) $35 \mathrm{~mm} / \mathrm{min}$

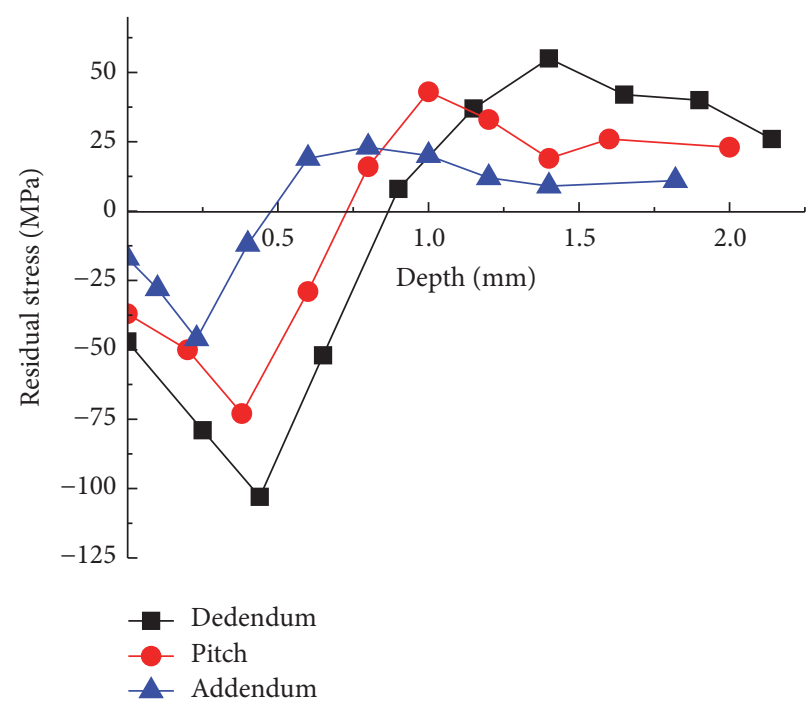

(b) $28 \mathrm{~mm} / \mathrm{min}$

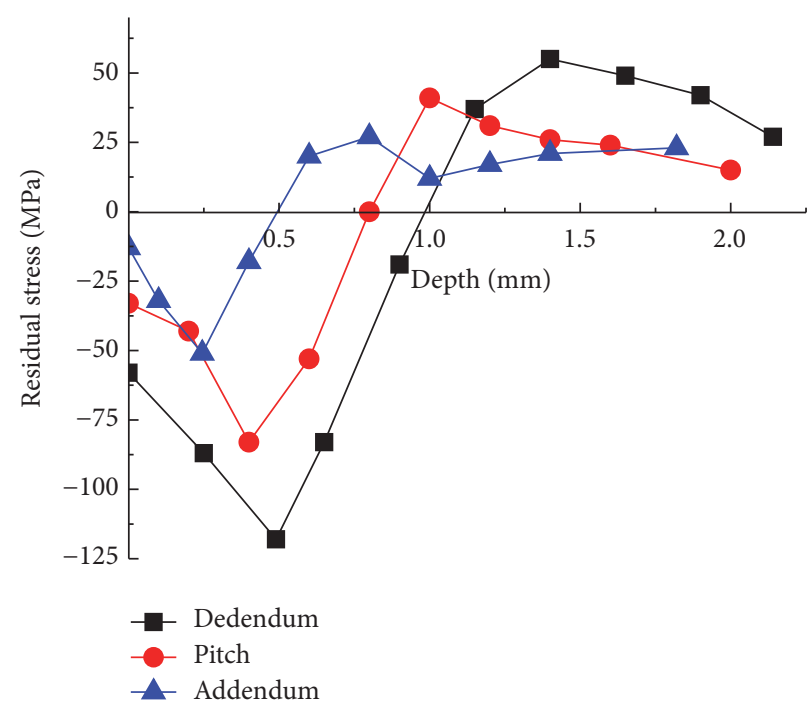

(d) $42 \mathrm{~mm} / \mathrm{min}$

FIGURE 8: Variation curves of the residual stress at a rotational speed of $1,428 \mathrm{r} / \mathrm{mm}$ at different feed rates.

of the spline addendum is gradually formed by the flow of the metal during the cold roll-beating process, the effect of force on the cold roll-beating is small. After the cold roll-beating process, the residual stress is released at this position; thus, the peak residual compressive stress at the addendum of the spline is the minimum value, and the increase of the peak residual compressive stress at the addendum is small as the rotational speed of the cold roll-beating increased.

The variations of the peak compressive residual stress curve with the feed rates of the spline at different rotational speeds are shown in Figure 15.

As shown in Figure 15, at different rotational speeds, the peak residual compressive stress at the dedendum, pitch, and the addendum of the cold rolling spline increased with an increase in the feed rate. The residual compressive stress at the dedendum exhibited the most significant increase, and the peak residual compressive stress at the pitch and the addendum is small due to an increase in the spline feed rate at the same speed rate. The amount of strike increased in the cold roll-beating process, and the deformation caused by the force of the cold roll-beating increased. The strain increased to the maximum value at the dedendum; thus, the peak residual stress at the dedendum also exhibited the most significant increase. With an increase in the feed rate, the storage range energy in the cold roll-beating process increased; the workpiece surface needs to balance the tensile stress within the depth of the workpiece in an extensive range. As the spline feed rate increased during the cold rolling process, the larger peak residual compressive stress is formed at the spline surface.

2.4.3. Variation in the Residual Layer Depth. The variation of the residual stress layer depth curve with rotational speeds is shown in Figure 16. 


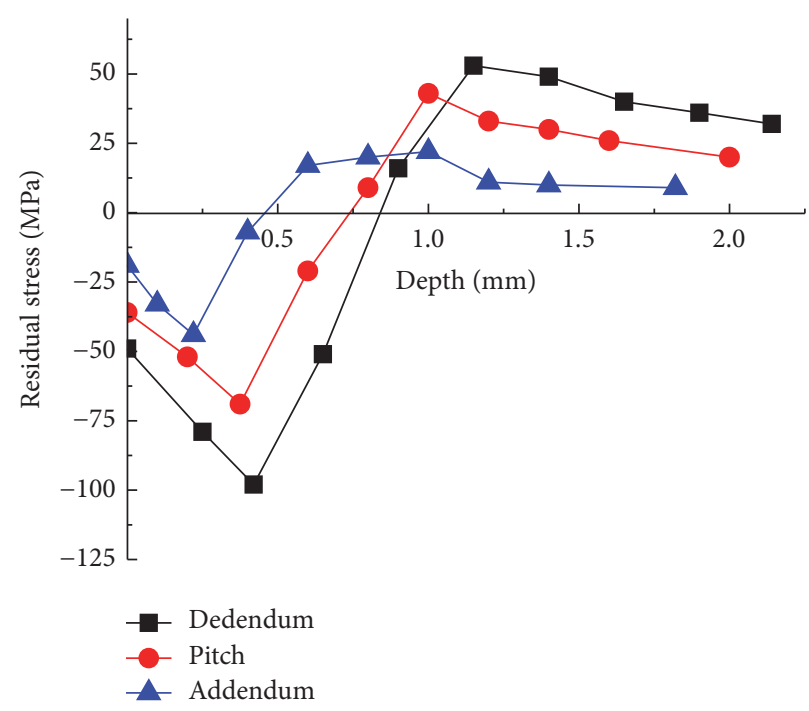

(a) $21 \mathrm{~mm} / \mathrm{min}$

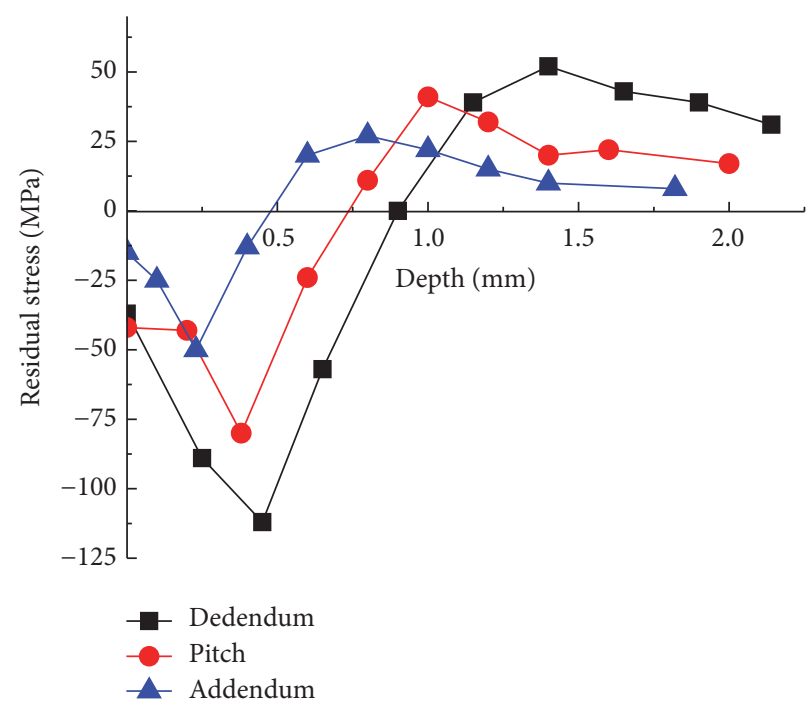

(c) $35 \mathrm{~mm} / \mathrm{min}$

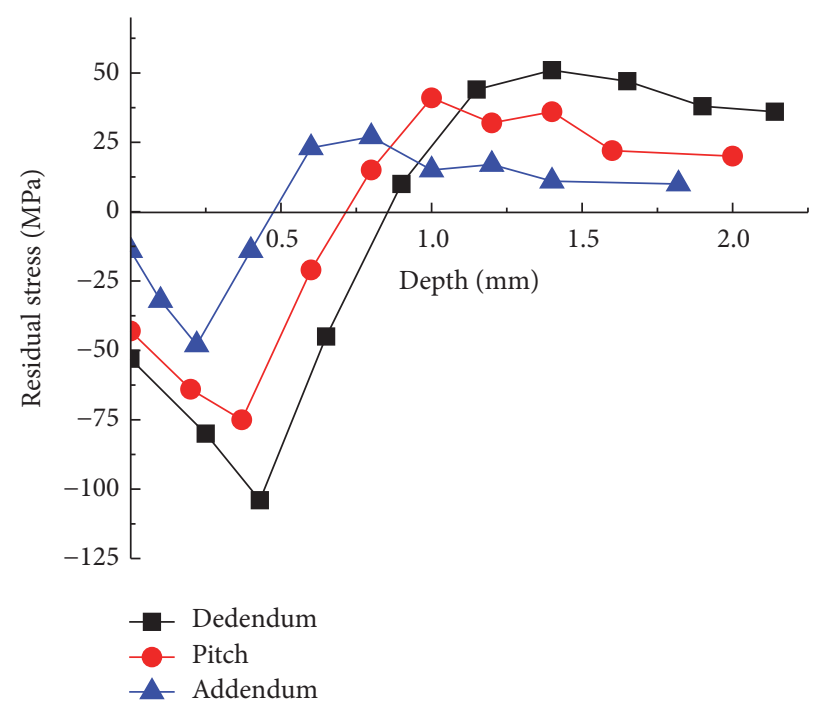

(b) $28 \mathrm{~mm} / \mathrm{min}$

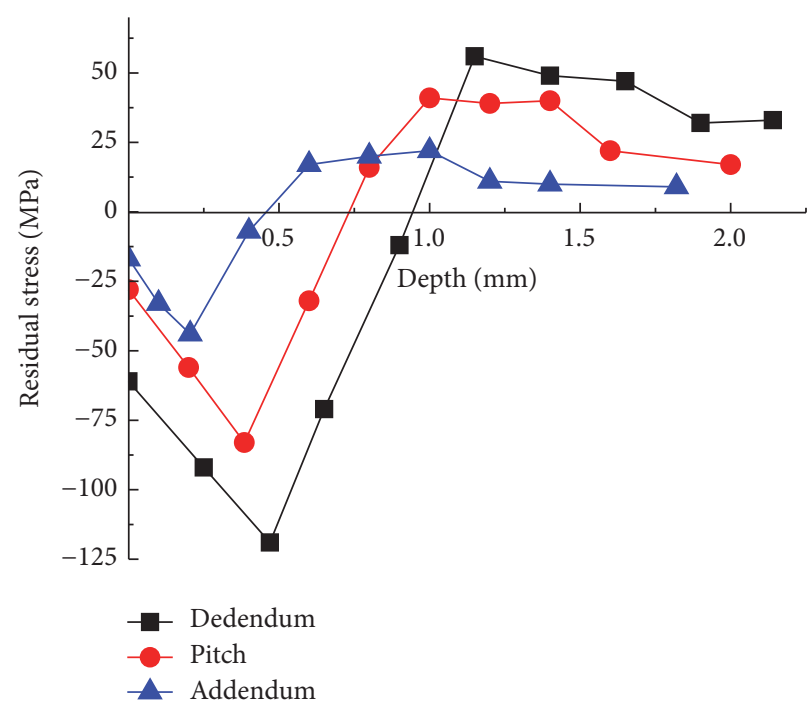

(d) $42 \mathrm{~mm} / \mathrm{min}$

FIGURE 9: Variation curves of the residual stress at a rotational speed of $1,581 \mathrm{r} / \mathrm{min}$ at different feed rates.

As shown in Figure 16, within the range of the cold roll-beating rotational speed and spline feed rate in the experiment, the residual compressive stress layer depth in the superficial spline profile in cold roll-beating indicates that the residual compressive stress layer depth at the dedendum is deeper than the residual compressive stress layer depth at the pitch. The residual compressive stress layer depth at the addendum is the smallest depth. With an increase in the rotational speed of the cold roll-beating, the residual compressive stress layer depth at the dedendum decreases, while the residual compressive stress layer depth at the pitch and addendum slightly decreases. The residual compressive stress layer depth ranges from 0.7 to $0.8 \mathrm{~mm}$ at the pitch. When the spline feed rate is large, the residual compressive stress layer depth at the dedendum increases because the increase in the cold roll-beating speed rate causes an increase in the peak residual compressive stress. However, an increase in the cold roll-beating speed rate causes a decrease in the amount of strike. Rolling rounds of a single hit were caused by the corresponding reduction in strain. The strain energy produced by the amount of strike is reduced, especially the spline feed rate, which is large in the cold roll-beating. With an increase in the rotational speed of the cold roll-beating, the amount of strike and the range of the cold roll-beating force decrease; thus, the residual compressive stress layer depth is reduced.

The curves of the relationship between the depth of the residual compressive stress layer and the feed rate of the spline for different cold roll-beating speeds are shown in Figure 17.

As shown in Figure 17, the residual compressive stress of the surface of the spline tooth profile increases with an increase in the spline feed rate amount during the cold rollbeating process. When the rotational speed of the cold rollbeating is $1428 \mathrm{r} / \mathrm{min}$ and $1581 \mathrm{r} / \mathrm{min}$, the residual compressive 


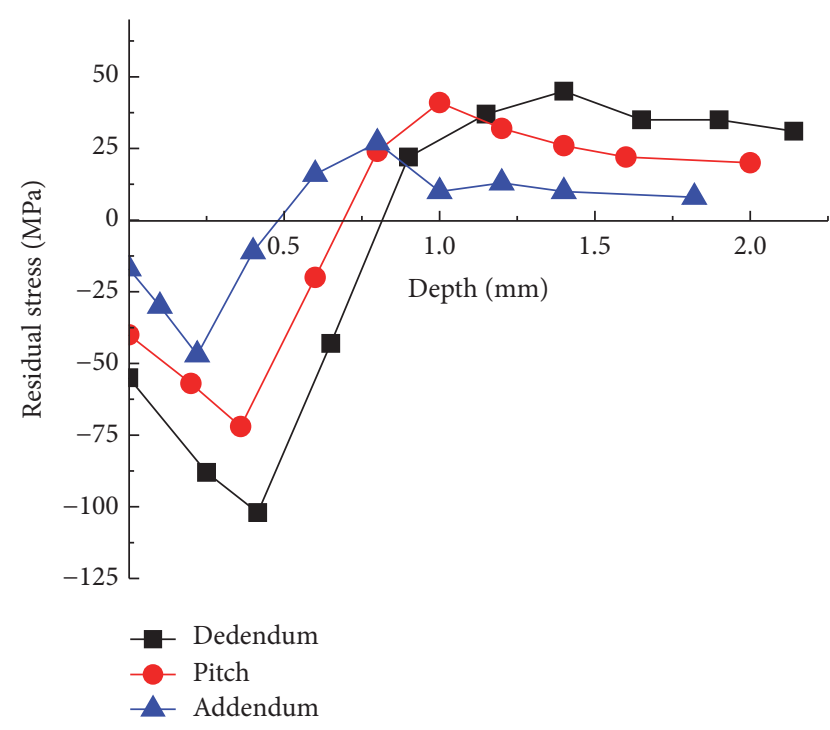

(a) $21 \mathrm{~mm} / \mathrm{min}$

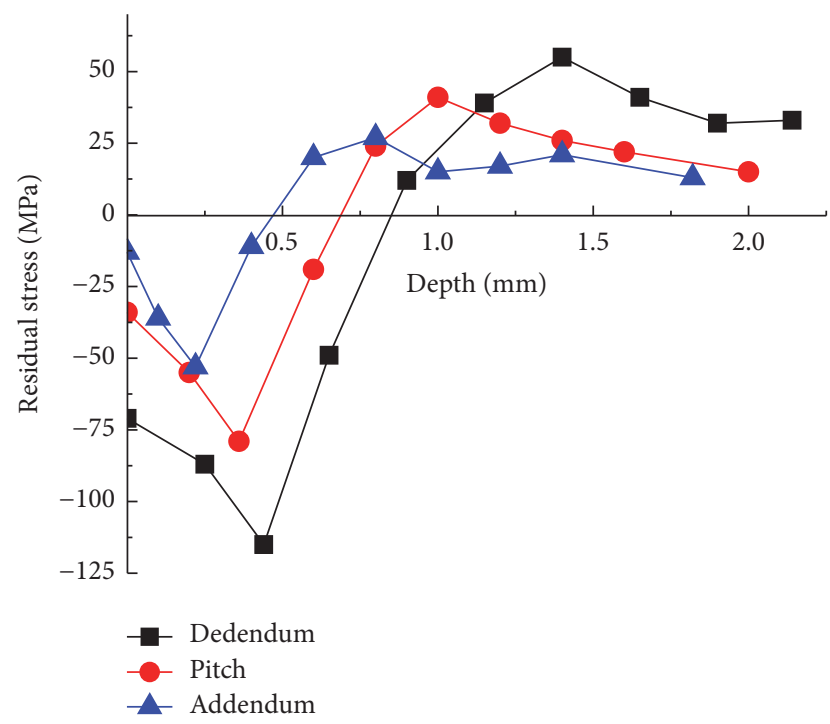

(c) $35 \mathrm{~mm} / \mathrm{min}$

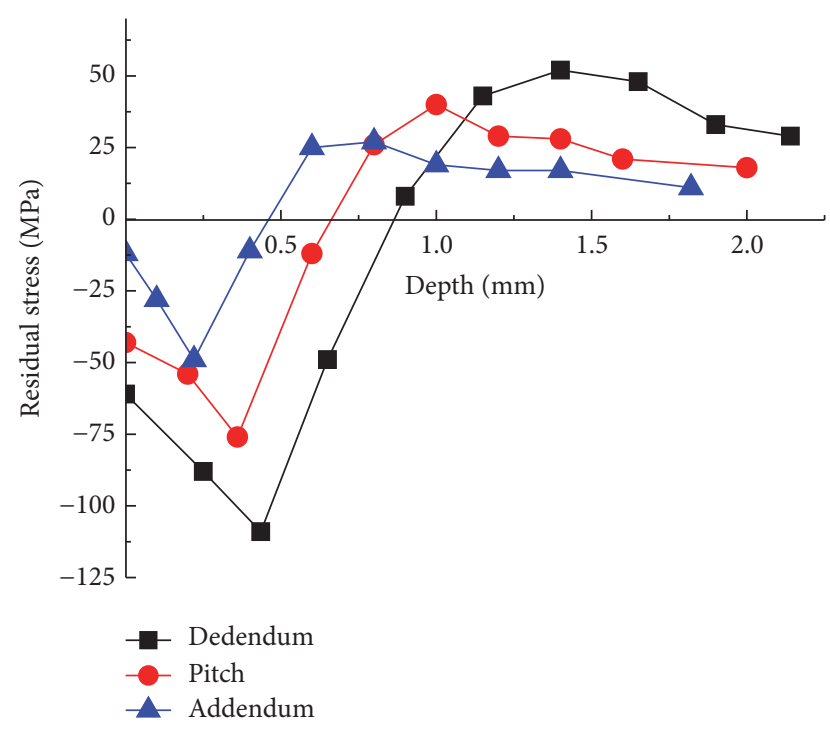

(b) $28 \mathrm{~mm} / \mathrm{min}$

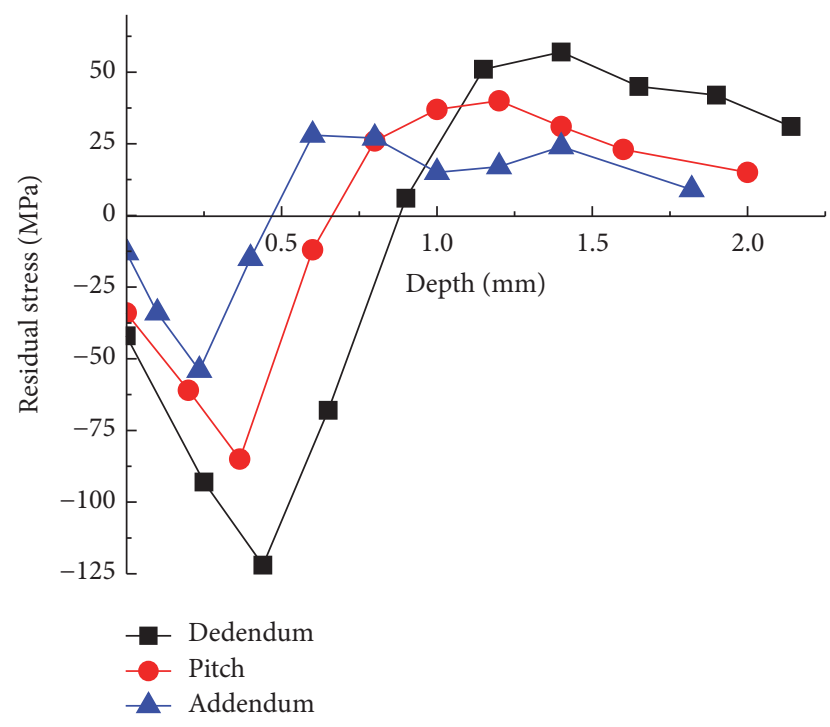

(d) $42 \mathrm{~mm} / \mathrm{min}$

FIGURE 10: Variation curves of the residual stress at a rotational speed of $1,806 \mathrm{r} / \mathrm{min}$ at different feed rates.

stress layer depth significantly increases. When the rotational speed of cold roll-beating is $1806 \mathrm{r} / \mathrm{min}, 2032 \mathrm{r} / \mathrm{min}$, and $2258 \mathrm{r} / \mathrm{min}$, the increase of residual stress layer is not obvious. This is due to the fact that the residual stress is produced by the uneven deformation of the workpiece material. In the high rotational speed, the workpiece material strain rate increased, causing the material flow stress to increase and the workpiece surface of the uneven degree of plastic deformation also increased. But the increase of speed led to the reduction of depth of a single hit; the scope of the impact of rolling force becomes smaller. Therefore, at high rotational speed, the increase gradient of the residual stress layer depth is small, and the gradient of the peak residual compressive stress decreases slowly. When the rotational speed of the cold roll-beating is $1428 \mathrm{r} / \mathrm{min}$ and $1581 \mathrm{r} / \mathrm{min}$, the depth of the residual compressive stress layer ranges from 0.84 to $0.98 \mathrm{~mm}$ at the pitch with different feed rates. The rotational speed is $1806 \mathrm{r} / \mathrm{min}$ and $2032 \mathrm{r} / \mathrm{min}$ when the different feed rates of cold roll-beating forming at the pitch of the residual pressure stress layer depth range from 0.71 to $0.73 \mathrm{~mm}$. This finding is due to the increase in the amount of spline feed rate, which causes the roller on the spline of the single shot to increase the amount of strike after an increase in the amount of deformation. The cold roll-bearing force eventually produces residual stress in the deeper surface of the spline surface. When the cold roll-beating rotational speed is $2258 \mathrm{r} / \mathrm{min}$ with different feed rates of cold roll-beating forming, the pitch circle at the residual compressive stress layer depth ranges from 0.68 to $0.73 \mathrm{~mm}$. This result is due to the increase in the rotational speed of the cold roll-beating, which causes 


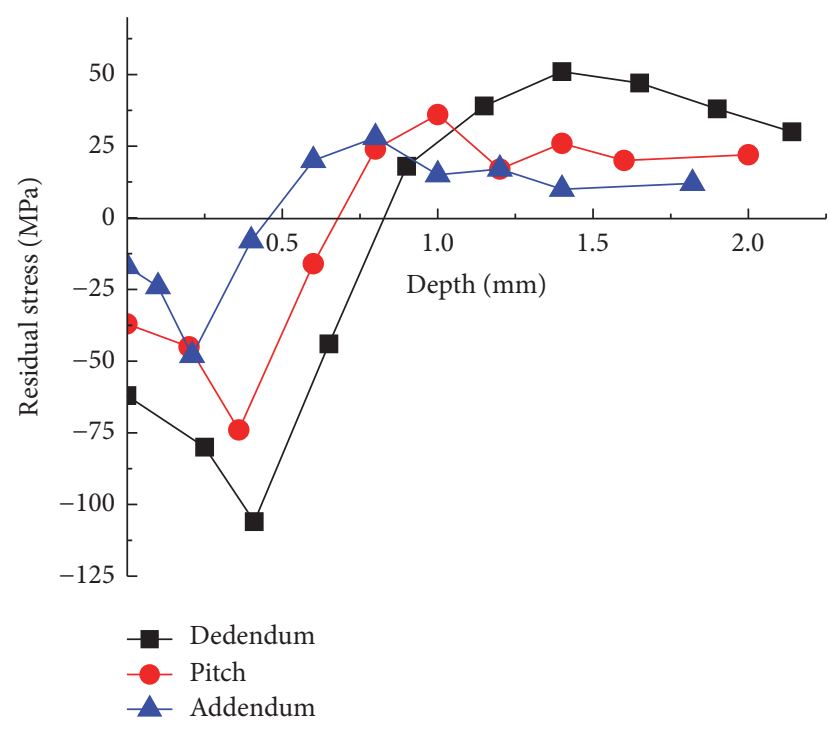

(a) $21 \mathrm{~mm} / \mathrm{min}$

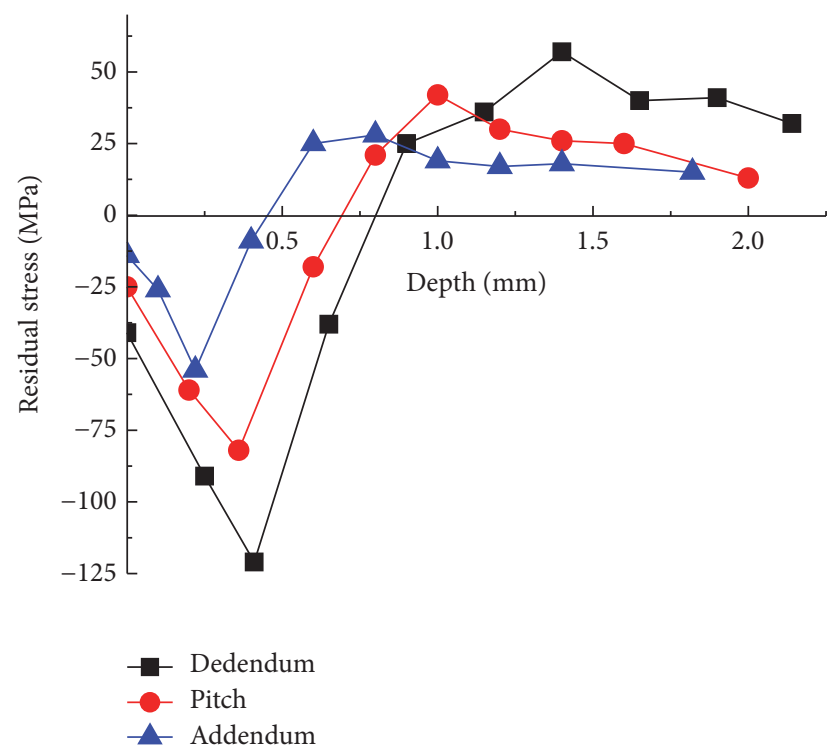

(c) $35 \mathrm{~mm} / \mathrm{min}$

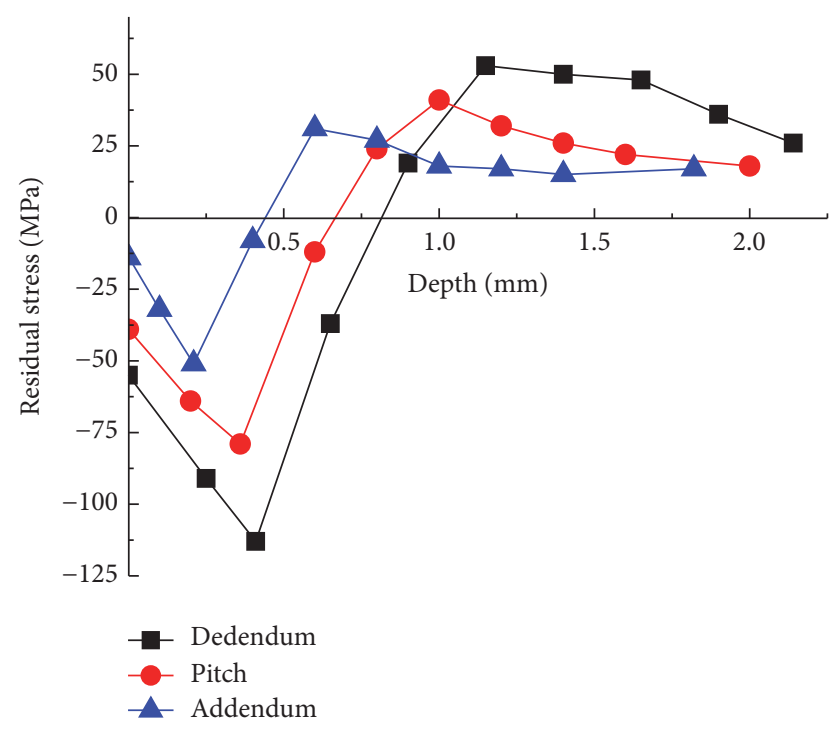

(b) $28 \mathrm{~mm} / \mathrm{min}$

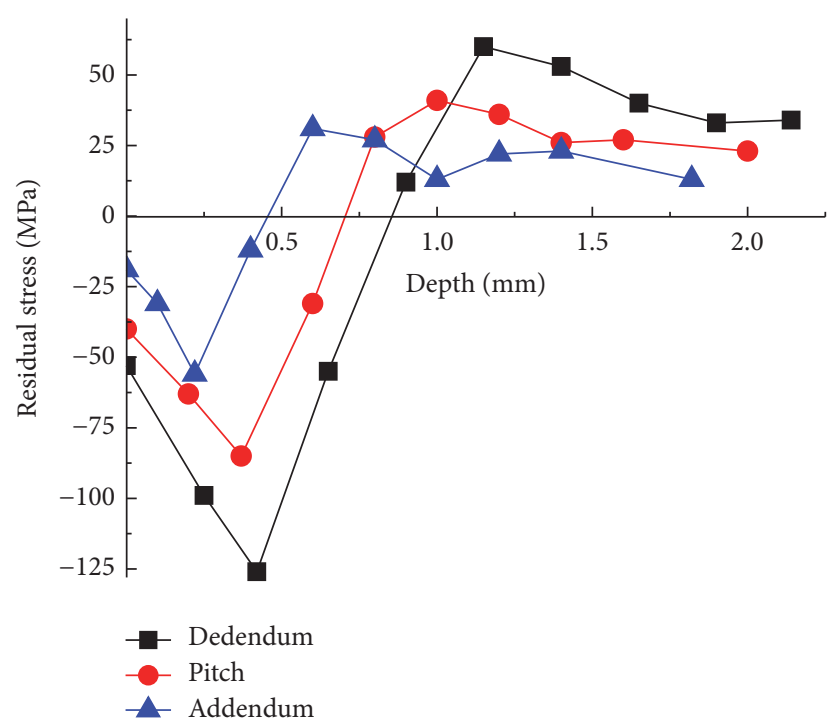

(d) $42 \mathrm{~mm} / \mathrm{min}$

FIGURE 11: Variation curves of the residual stress at a rotational speed of 2,032 r/min at different feed rates.

a reduction in the number of hits of the roller to the spline, the effect range of the roll-beating force, and the depth of the residual compressive stress layer.

\section{Model of the Surface Residual Stress Distribution of the Spline Shaft Profile}

The response surface method has many advantages, such as the ability to rotate, sequential nature, model stability, and reduced test times; the method is often employed to solve practical problems because the response estimation results can approach the real response surface and achieve a satisfactory prediction.

The experimental results reveal that the influence of the rotational speed and feed rate of the spline on the residual stress is not independent, and the relationship between the peak and depth layer of the residual stress curve is nonlinear. Therefore, the second-order estimation regression equation is employed to establish the surface response model of the residual stress distribution with variations in the cold rollbeating parameters.

The second-order regression prediction model of the rollbearing rotational speed and feed rate interaction of the two factors is given by

$$
y(x)=\varepsilon+\beta_{1} x_{1}+\beta_{2} x_{2}+\beta_{12} x_{1} x_{2}+\beta_{11} x_{1}^{2}+\beta_{22} x_{2}^{2},
$$

where $x_{1}$ is the rotational speed $n \mathrm{in} \mathrm{r} / \mathrm{min}$ and $x_{2}$ is the feed rate $f$ in $\mathrm{mm} / \mathrm{min}$. 


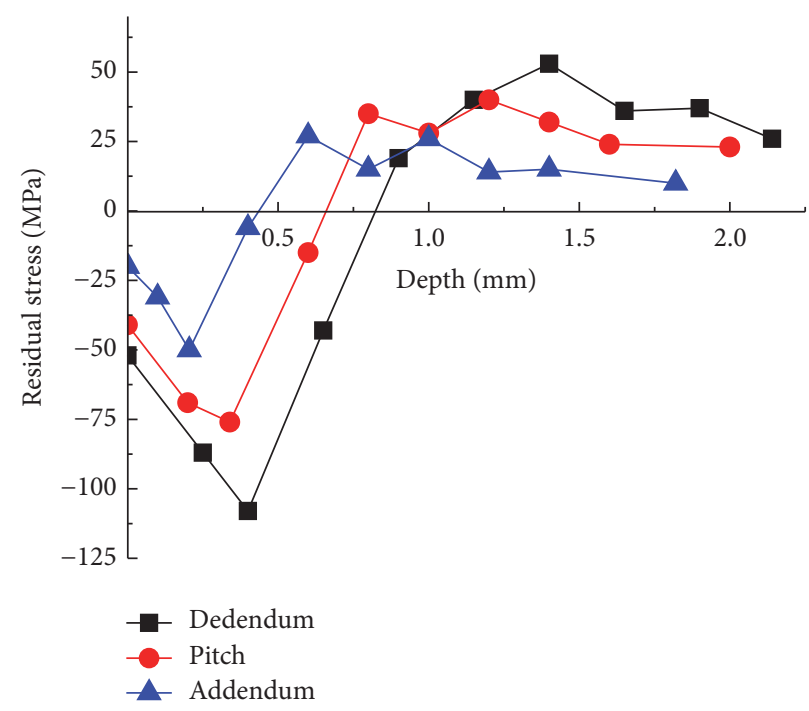

(a) $21 \mathrm{~mm} / \mathrm{min}$

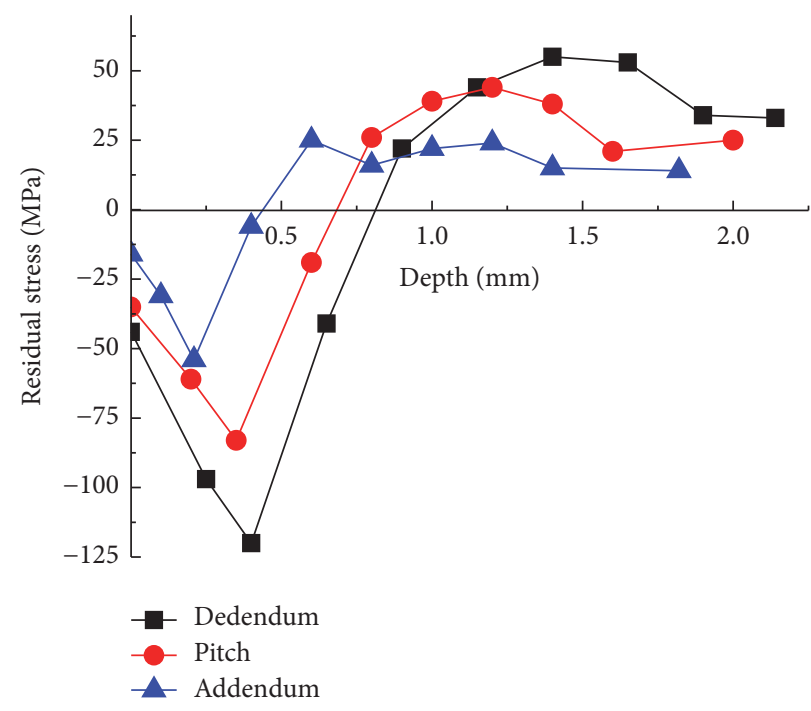

(c) $35 \mathrm{~mm} / \mathrm{min}$

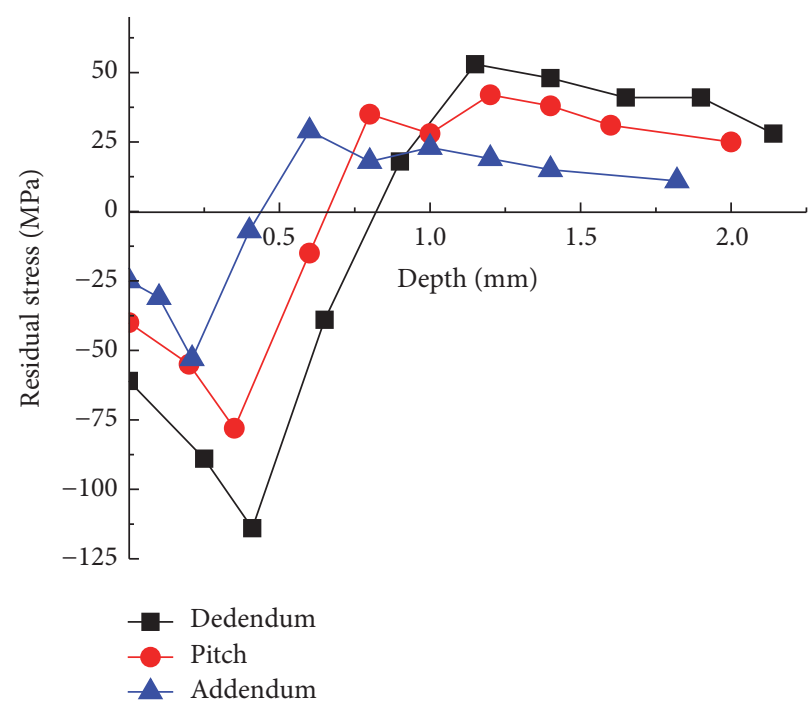

(b) $28 \mathrm{~mm} / \mathrm{min}$

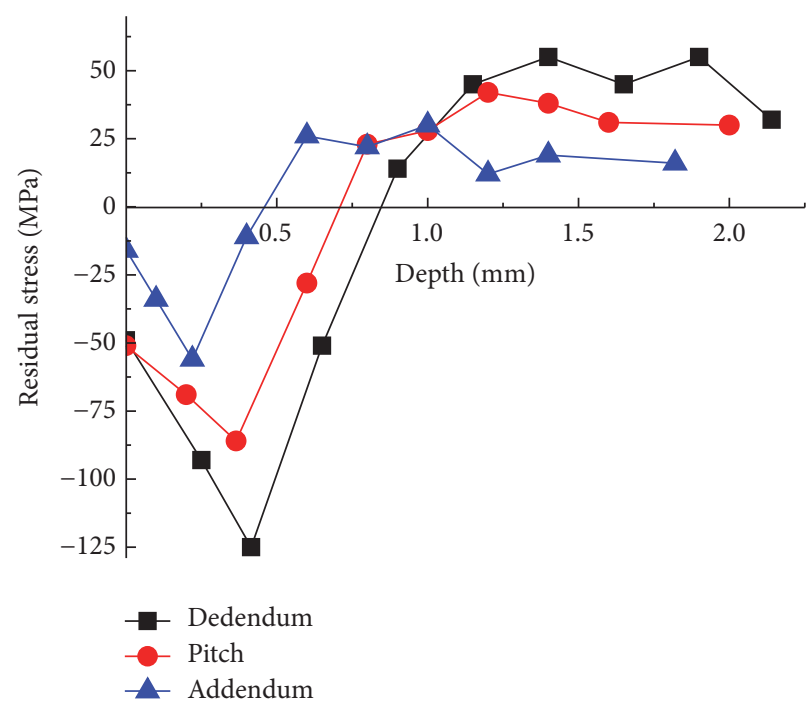

(d) $42 \mathrm{~mm} / \mathrm{min}$

FIGURE 12: Variation curves of the residual stress at a rotational speed of 2,258 r/min at different feed rates.

3.1. Model of the Peak Value of the Residual Compressive Stress of Cold Roll-Beating. The peak value of the residual stress on the surface of the tooth profile is the dependent variable, and the rolling wheel speed $n$ and the spline feed rate $f$ are the independent variables. Using the experimental data, the roll-beating rotational speeds are $1,428,1,581,1,806$, and $2,032 \mathrm{r} / \mathrm{min}$, and the spline feed rates are $21,28,35$, and $42 \mathrm{~mm} / \mathrm{min}$. Fitting for formula (1), establish a relationship model between the peak residual compressive stress and the parameter of cold roll-beating of the three positions in the spline tooth profile at the dedendum, pitch, and addendum.

The model of the peak value of compressive residual stress of the dedendum is expressed as follows:

$$
\begin{aligned}
\sigma_{\mathrm{RS} 1}= & -80.8066+0.0241 n-1.3439 f \\
& +0.00015603 n f-0.000012987 n^{2}+0.0013 f^{2} .
\end{aligned}
$$

The model of the peak value of compressive residual stress of the pitch is expressed as follows:

$$
\begin{aligned}
\sigma_{\mathrm{RS} 2}= & -22.7056-0.0135 n-1.7406 f \\
& +0.00040866 n f-0.000001915 n^{2}+0.0064 f^{2}
\end{aligned}
$$

The model of the peak value of the compressive residual stress of the addendum is as follows:

$$
\begin{aligned}
\sigma_{\mathrm{RS} 3}= & 15.1303-0.0389 n-1.1411 f+0.00014709 n f \\
& +0.000007294 n^{2}+0.0077 f^{2}
\end{aligned}
$$

After calculation, the test results from the three models are listed in Table 2. 


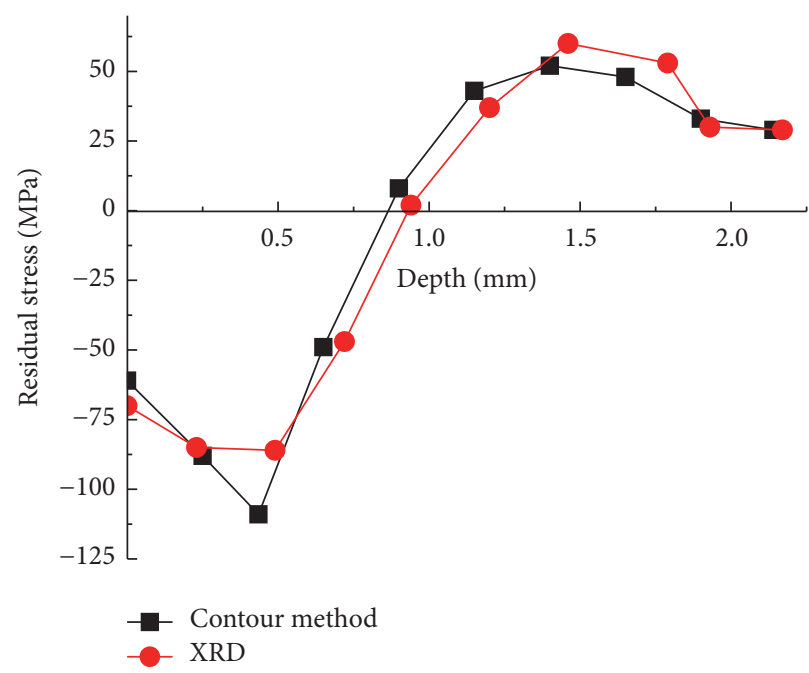

(a) Dedendum

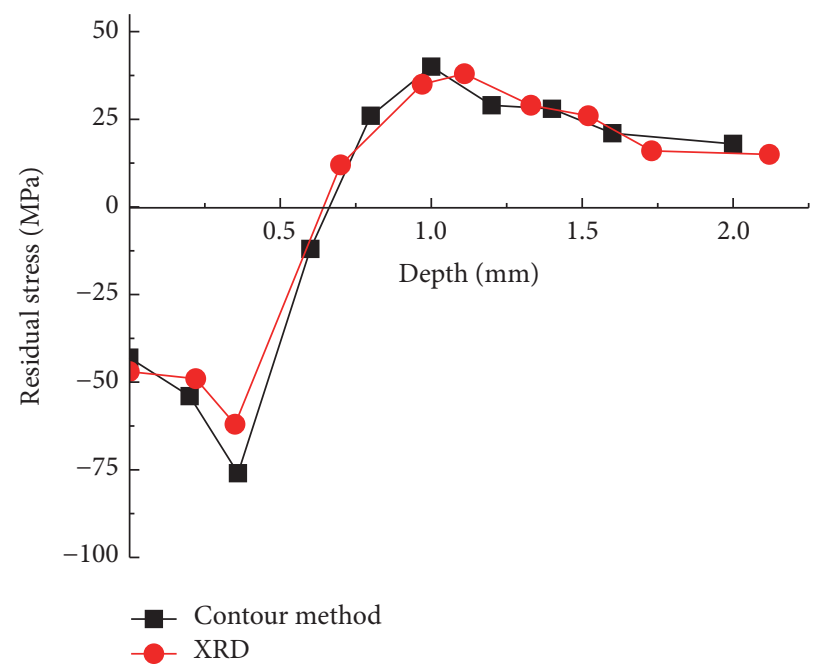

(b) Pitch

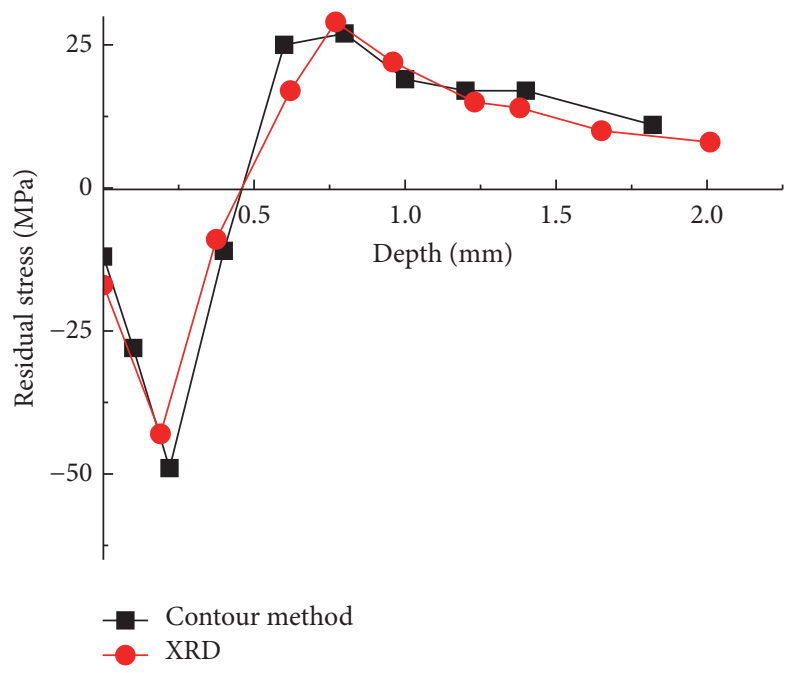

(c) Addendum

FIGURE 13: The contrast of the residual stress measured by the contour method and the XRD method.

TABLE 2: Test results from the prediction model for the peak residual stress.

\begin{tabular}{|c|c|c|c|c|c|c|}
\hline & Source of variance & Sum of square & Degree of freedom & Complex correlation coefficient & $F$ value & $F_{0.05}$ \\
\hline \multirow{3}{*}{ Dedendum } & SSR & 1193.2 & 5 & \multirow{3}{*}{0.997} & \multirow{3}{*}{636.24} & \multirow{3}{*}{3.33} \\
\hline & SSE & 3.7507 & 10 & & & \\
\hline & SSE & 1197.0 & 15 & & & \\
\hline \multirow{3}{*}{ Pitch } & SSR & 454.5369 & 5 & \multirow{3}{*}{0.9883} & \multirow{3}{*}{168.52} & \multirow{3}{*}{3.33} \\
\hline & SSE & 5.4006 & 10 & & & \\
\hline & SST & 459.93 & 15 & & & \\
\hline \multirow{3}{*}{ Addendum } & SSR & 234.5072 & 5 & \multirow{3}{*}{0.9864} & \multirow{3}{*}{144.63} & \multirow{3}{*}{3.33} \\
\hline & SSE & 3.2428 & 10 & & & \\
\hline & SST & 237.8 & 15 & & & \\
\hline
\end{tabular}

The test results for the peak residual stress values, which are listed in Table 2, illustrate that the $F$ value is substantially larger than $F_{0.05}$, which indicates that the confidence levels of the three models exceed $95 \%$ and also indicates high accuracy of the prediction results. The correlation coefficients $R^{2}$ in the three models are 99.7\%, 98.83\%, and 98.64\%, which indicate that the fitting results are reliable and the correlation between the predicted values and measured values is strong.

According to the model of the residual compressive stress peak of the tooth profile established by formulas (2)-(4), the 


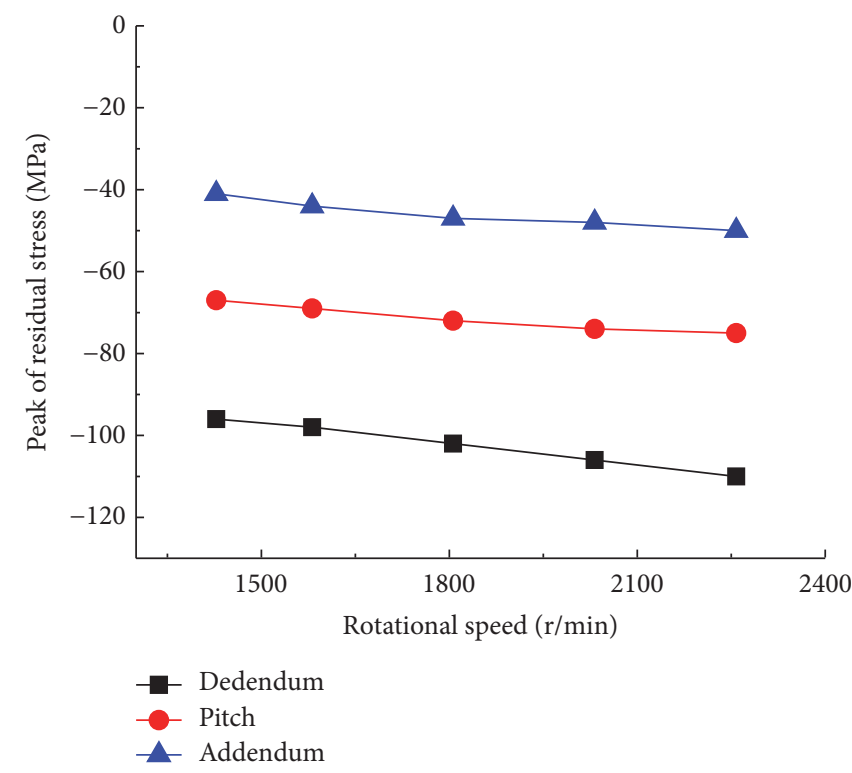

(a) $21 \mathrm{~mm} / \mathrm{min}$

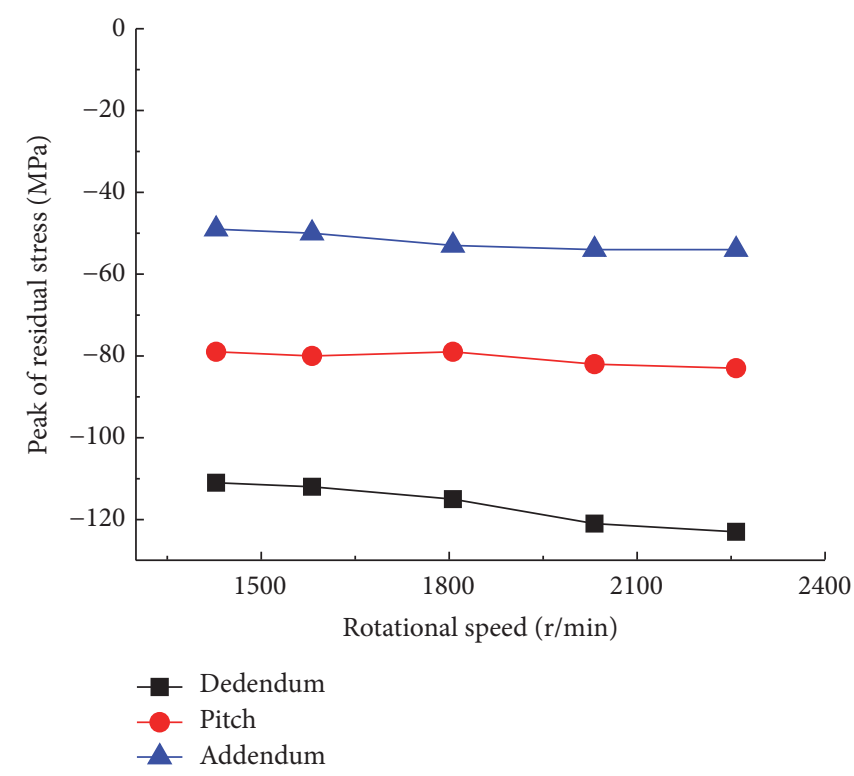

(c) $35 \mathrm{~mm} / \mathrm{min}$

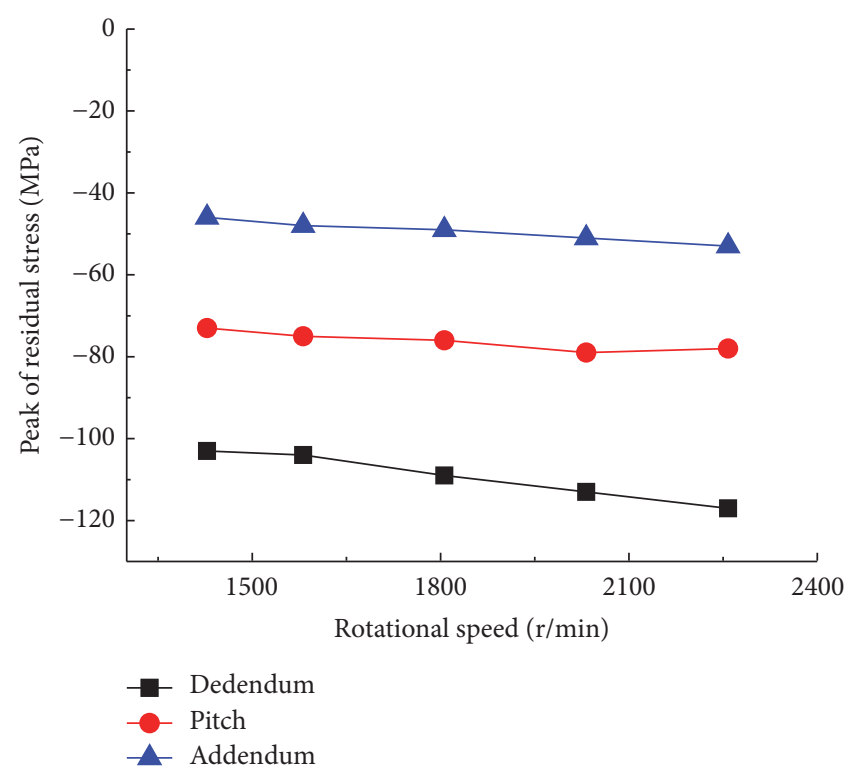

(b) $28 \mathrm{~mm} / \mathrm{min}$

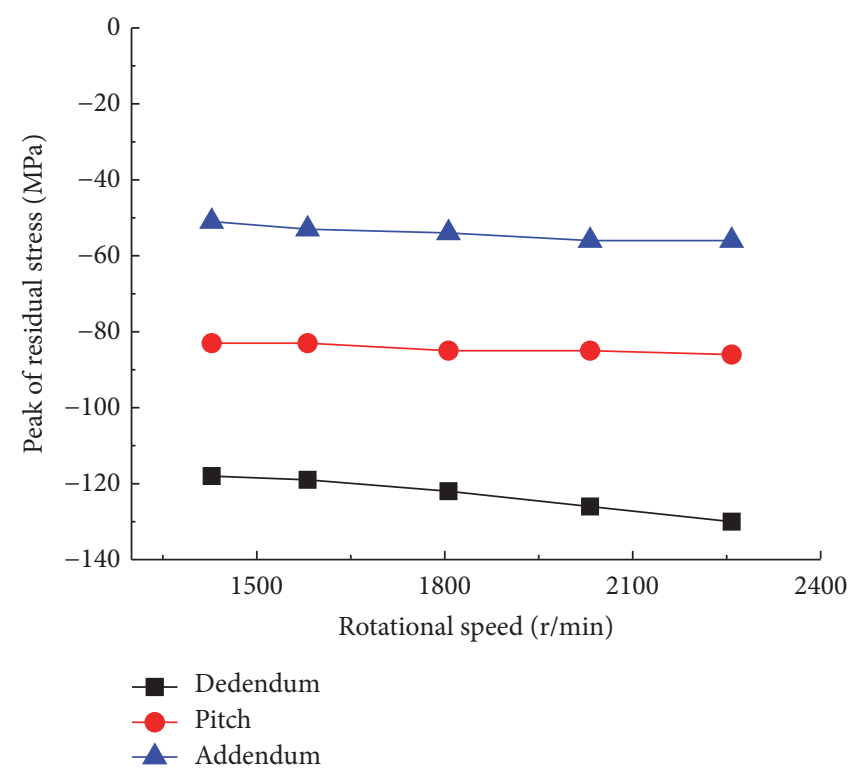

(d) $42 \mathrm{~mm} / \mathrm{min}$

FIGURE 14: Variation of the peak compressive residual stress curve with rotational speeds at different feed rates.

response surface of the residual stress peak of the tooth profile with the cold roll-beating speed and spline feed rate is shown in Figure 18.

The response surface shown in Figure 18 illustrates that the peak of the residual stress increases with an increase in the roll-beating speed when the feed rate of cold roll-beating is constant but the amplitude of the increase is not large. When the cold roll-beating's rotational speed is constant, the increase in the residual stress peak with an increase in the feed rate is large, especially in the dedendum part.

3.2. Establishment of the Depth Model for the Residual Compressive Stress Layer of Cold Roll-Beating. With the depth of the residual stress layer on the surface of the spline tooth profile as the dependent variable and the roll-beating rotational speed $n$ and spline feed rate $f$ as the independent variables and using the experimental data, the cold roll-beating rotational speeds are $1,428,1,581,1,806$, and $2,032 \mathrm{r} / \mathrm{min}$, and the spline feed rates are $21,28,35$, and $42 \mathrm{~mm} / \mathrm{min}$. Fitting for formula (1) establishes a relationship model between the residual compressive stress layer depths and the parameter of cold roll-beating of the three positions in the spline tooth profile at the dedendum,pitch, and addendum. The model of the residual compressive stress layer depth of the dedendum is expressed as follows: 


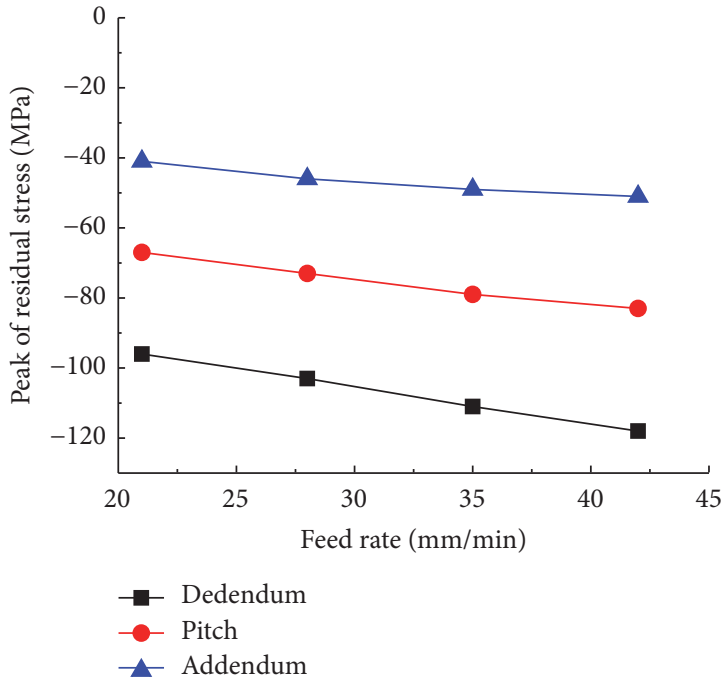

(a) $1428 \mathrm{r} / \mathrm{min}$

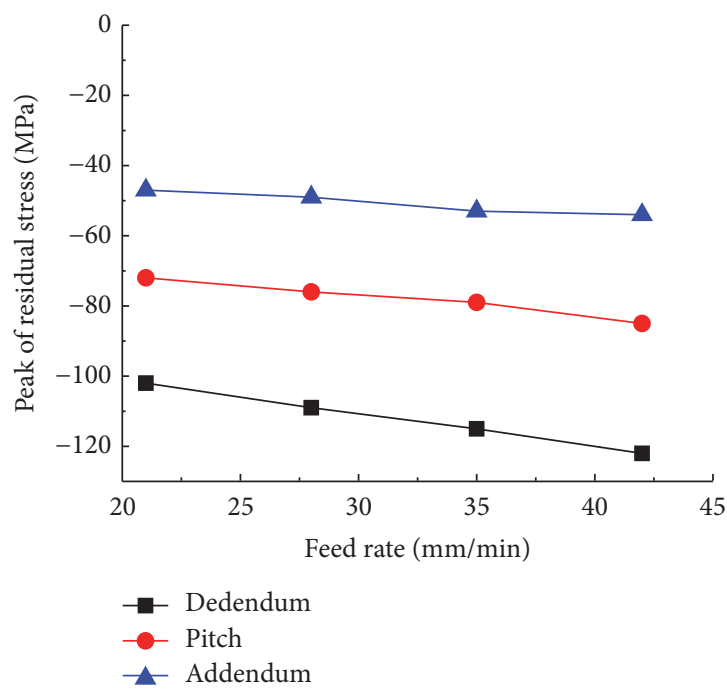

(c) $1806 \mathrm{r} / \mathrm{min}$

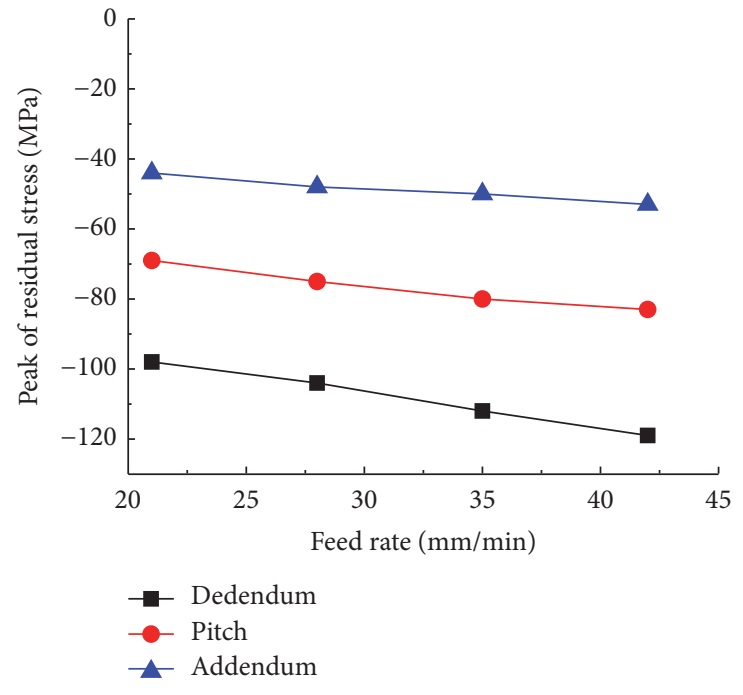

(b) $1581 \mathrm{r} / \mathrm{min}$

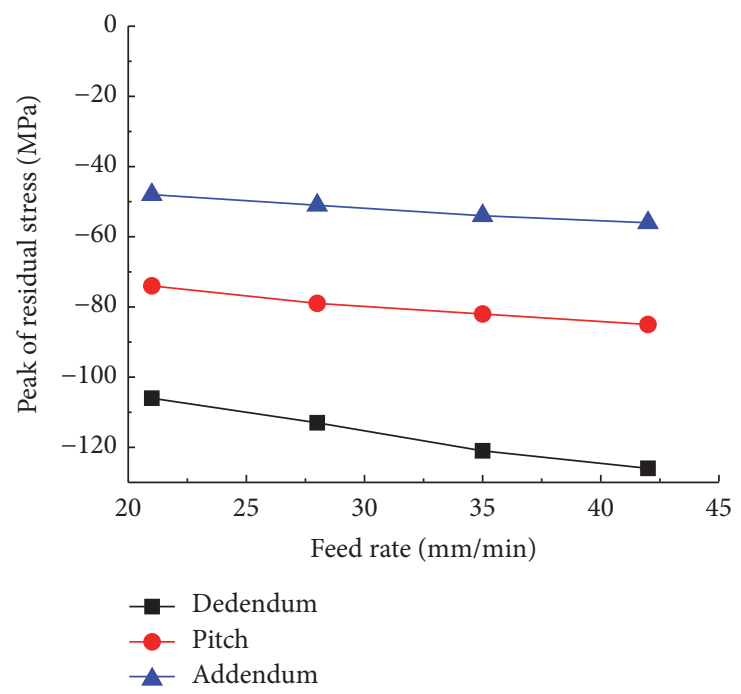

(d) $2032 \mathrm{r} / \mathrm{min}$

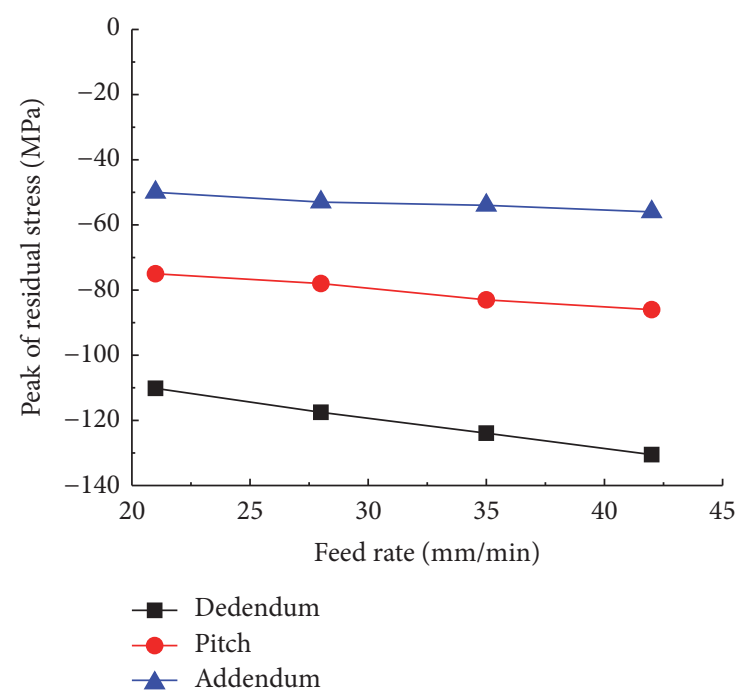

(e) $2258 \mathrm{r} / \mathrm{min}$

FIGURE 15: Variation of the peak compressive residual stress curve with the feed rates of the spline at different rotational speeds. 


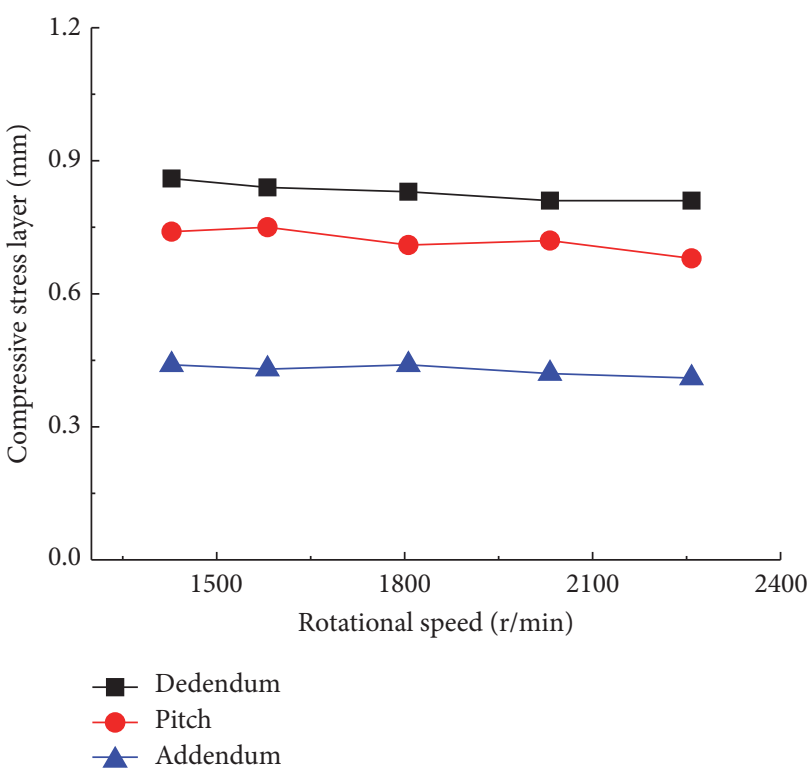

(a) $21 \mathrm{~mm} / \mathrm{min}$

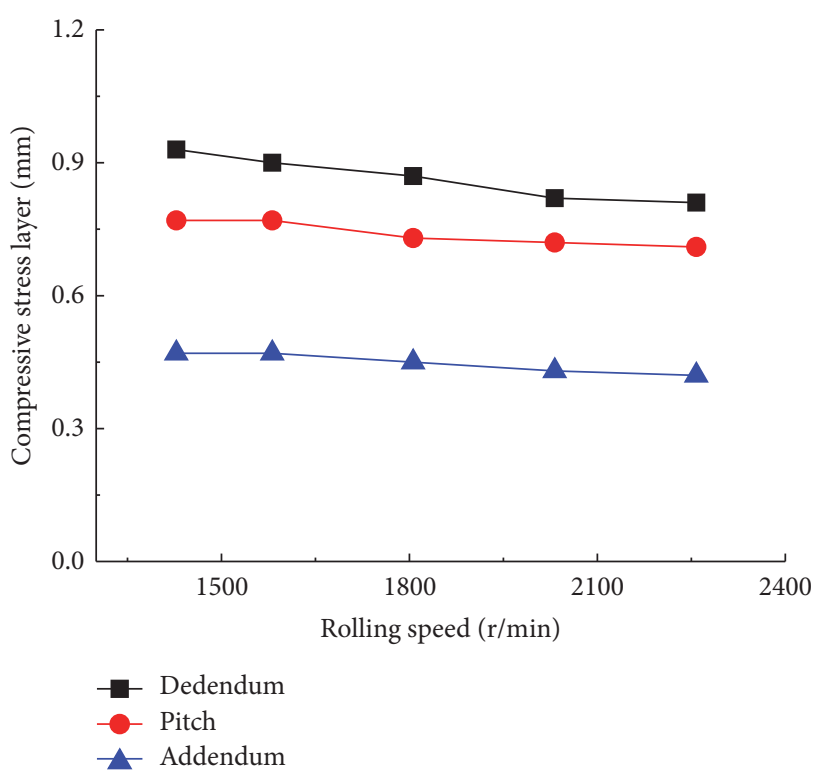

(c) $35 \mathrm{~mm} / \mathrm{min}$

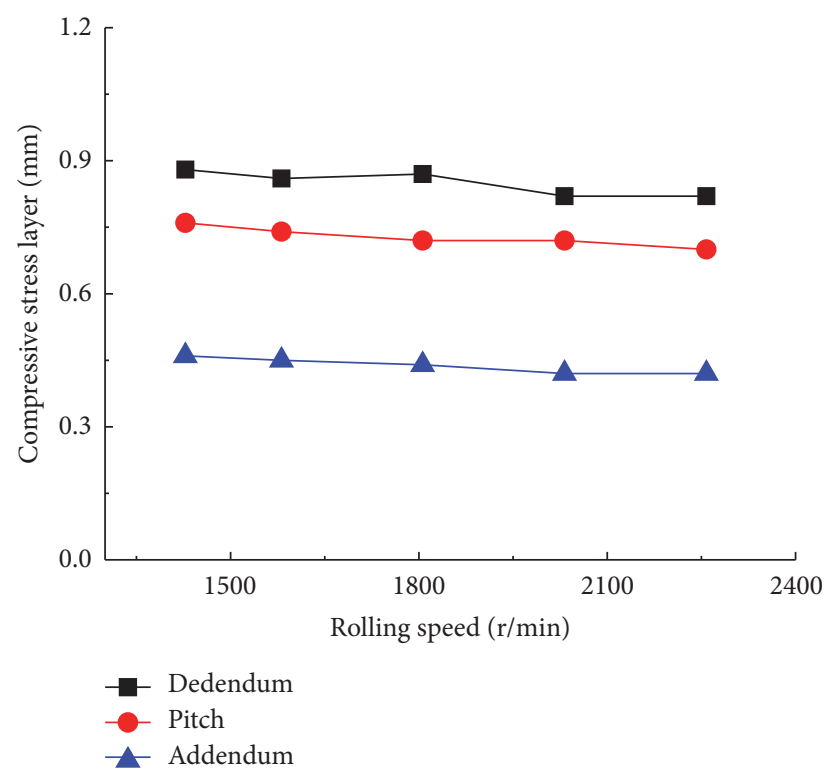

(b) $28 \mathrm{~mm} / \mathrm{min}$

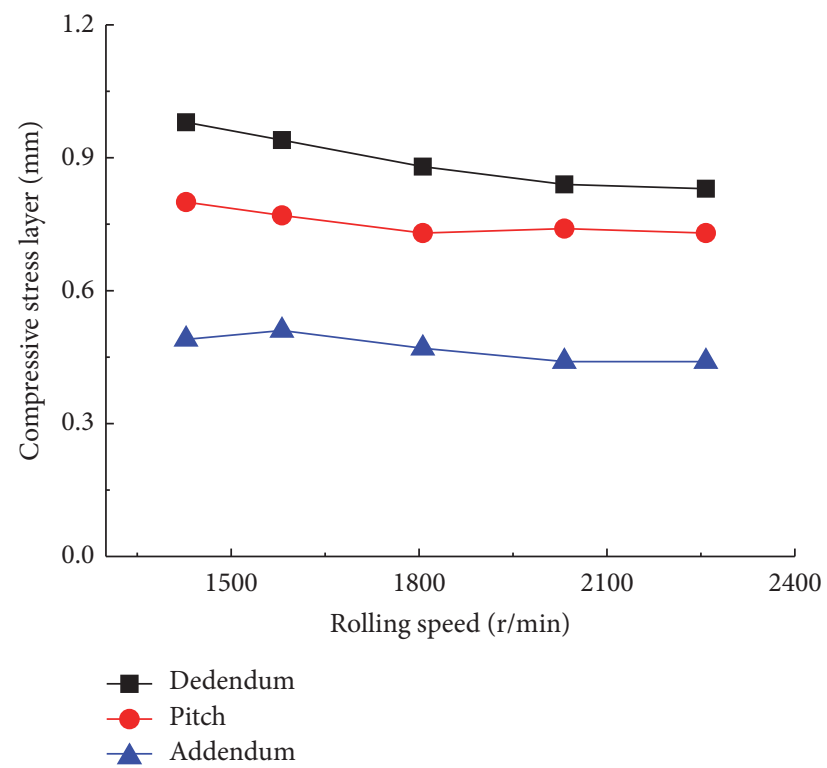

(d) $42 \mathrm{~mm} / \mathrm{min}$

FIGURE 16: Variation of the residual stress layer depth curve with rotational speeds.

$$
\begin{aligned}
D_{\mathrm{RS} 1}= & 0.5290+0.0002007 n+0.0149 f \\
& -0.0000080521 n f-0.00000002607 n^{2} \\
& +0.000038265 f^{2} .
\end{aligned}
$$

The model of the residual compressive stress layer depth of the pitch is expressed as follows:

$$
\begin{aligned}
D_{\mathrm{RS} 2}= & 1.1310-0.0004789 n+0.0037 f \\
& -0.0000027244 n f+0.000000138995 n^{2} \\
& +0.000038265 f^{2} .
\end{aligned}
$$

The model of the residual compressive stress layer depth of the addendum is expressed as follows:

$$
\begin{aligned}
D_{\mathrm{RS} 3}= & 0.0490+0.0004266 n+0.0037 f \\
& -0.0000032495 n f-0.000000112131 n^{2} \\
& +0.000063776 f^{2} .
\end{aligned}
$$

The significance test and variance analysis were applied to models (5)-(7). The results of the significance test are listed in Table 3.

The significance test results of the residual stress layer depth in Table 3 show that the $F$ value is greater than 0.05 . 


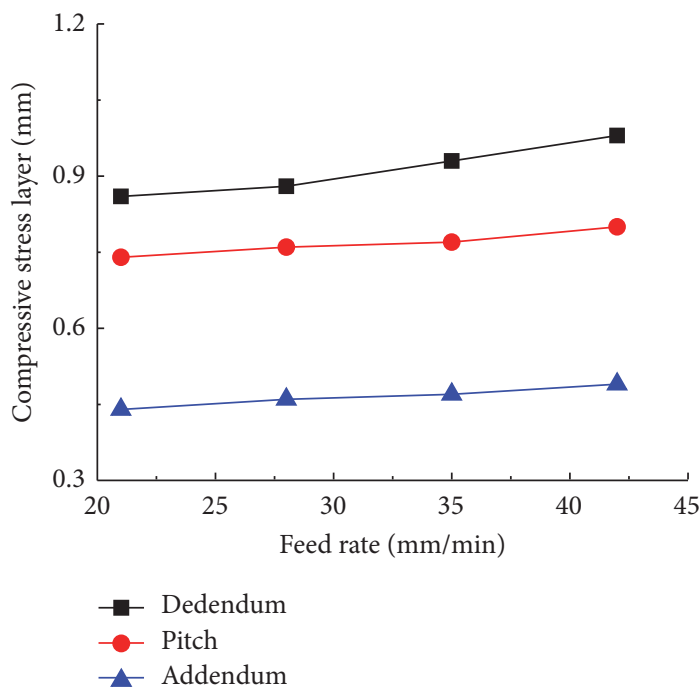

(a) $1428 \mathrm{r} / \mathrm{min}$

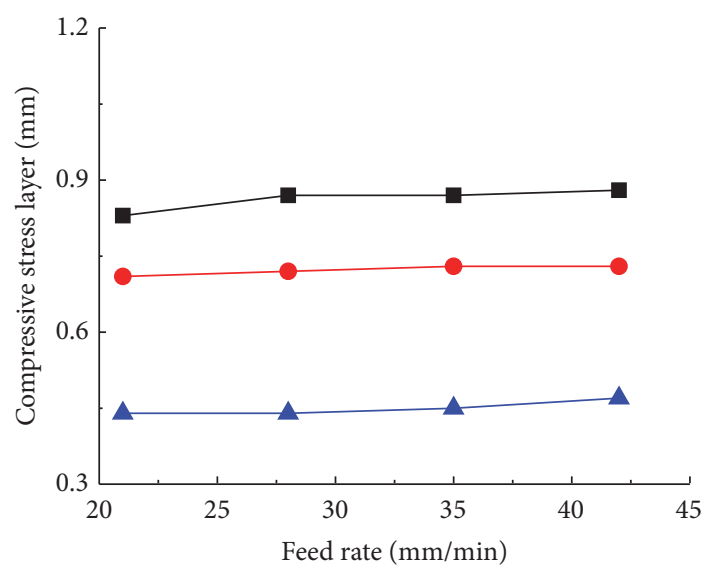

- Dedendum

- Pitch

- Addendum

(c) $1806 \mathrm{r} / \mathrm{min}$

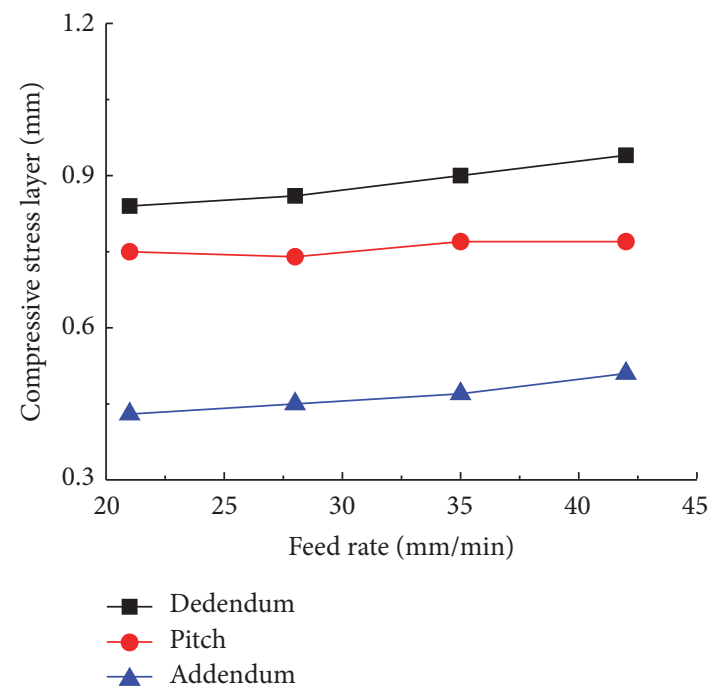

(b) $1581 \mathrm{r} / \mathrm{min}$

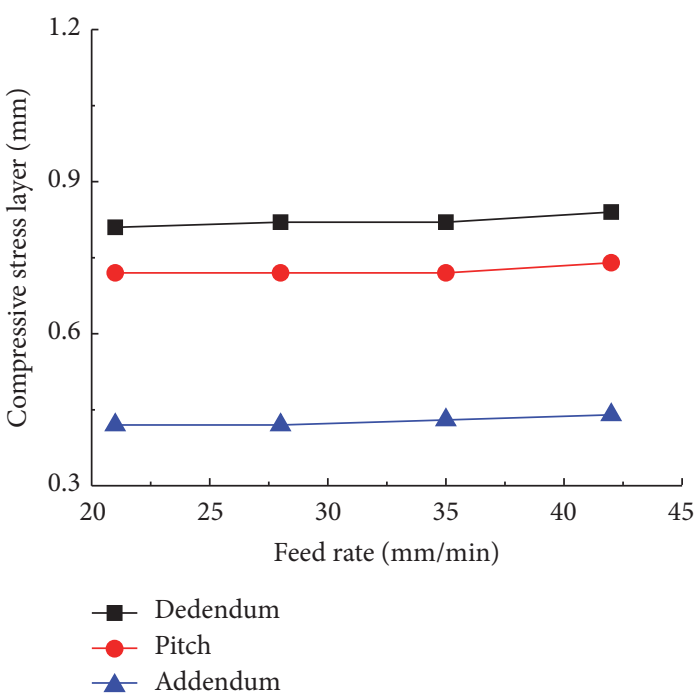

(d) $2032 \mathrm{r} / \mathrm{min}$

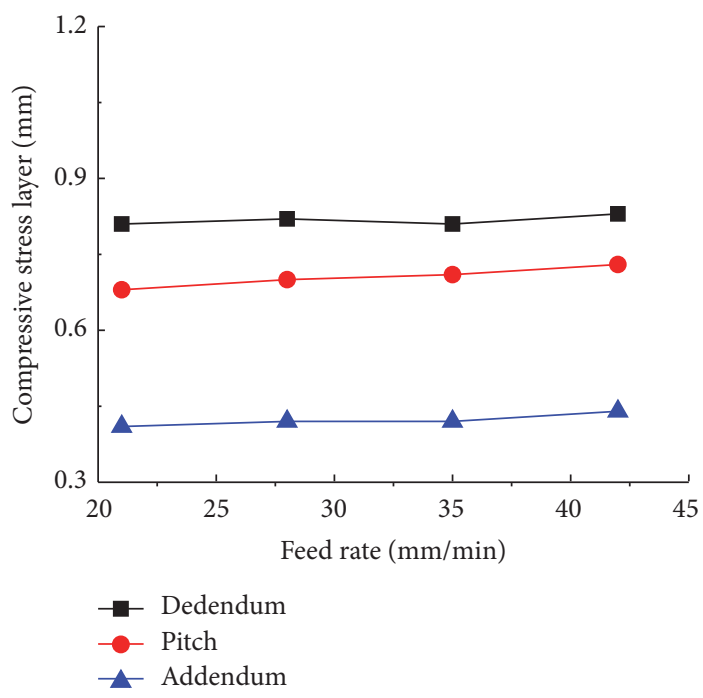

(e) $2258 \mathrm{r} / \mathrm{min}$

FIGURE 17: Curves of the residual compressive stress depth as a function of the workpiece feed rate. 


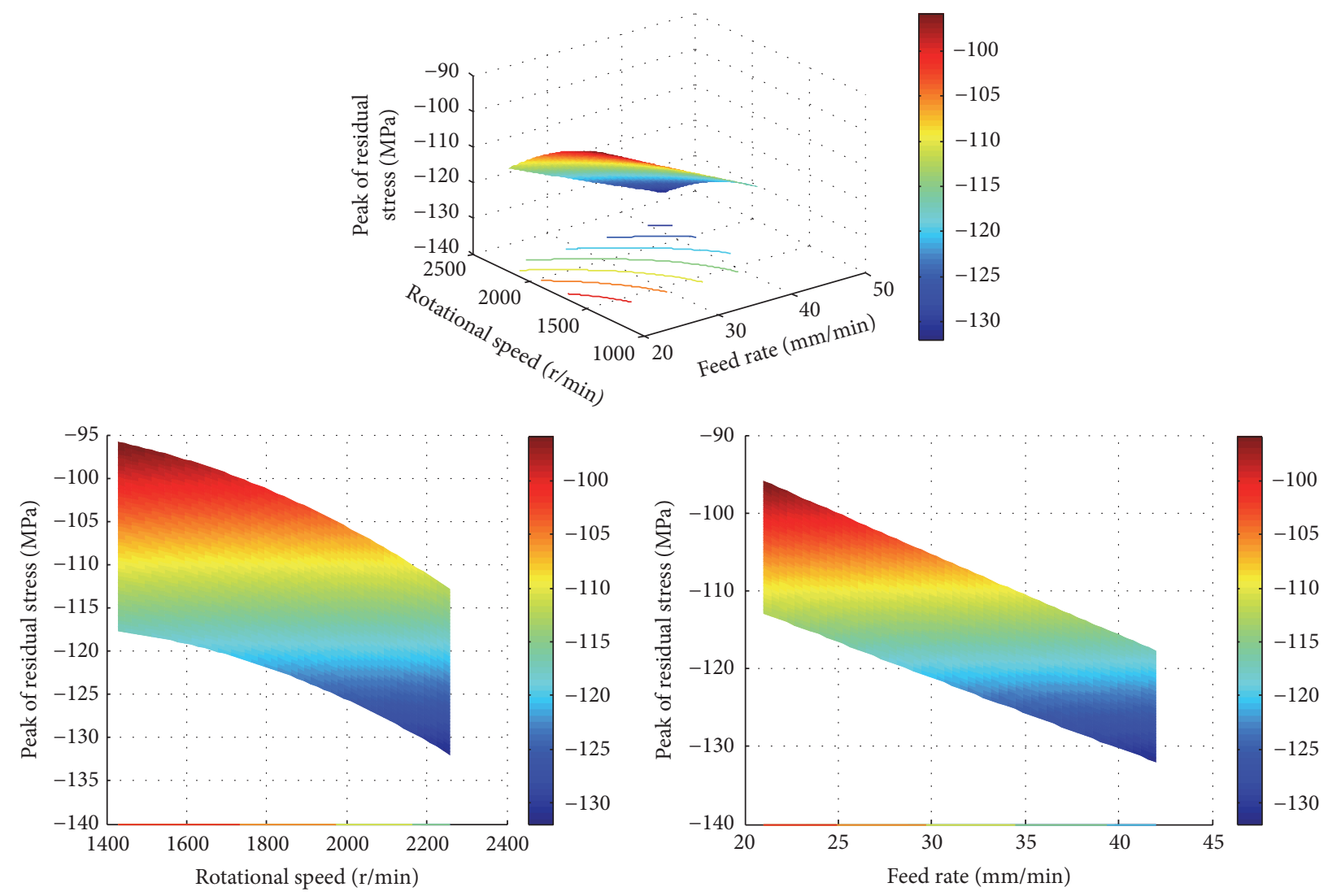

(a) Dedendum
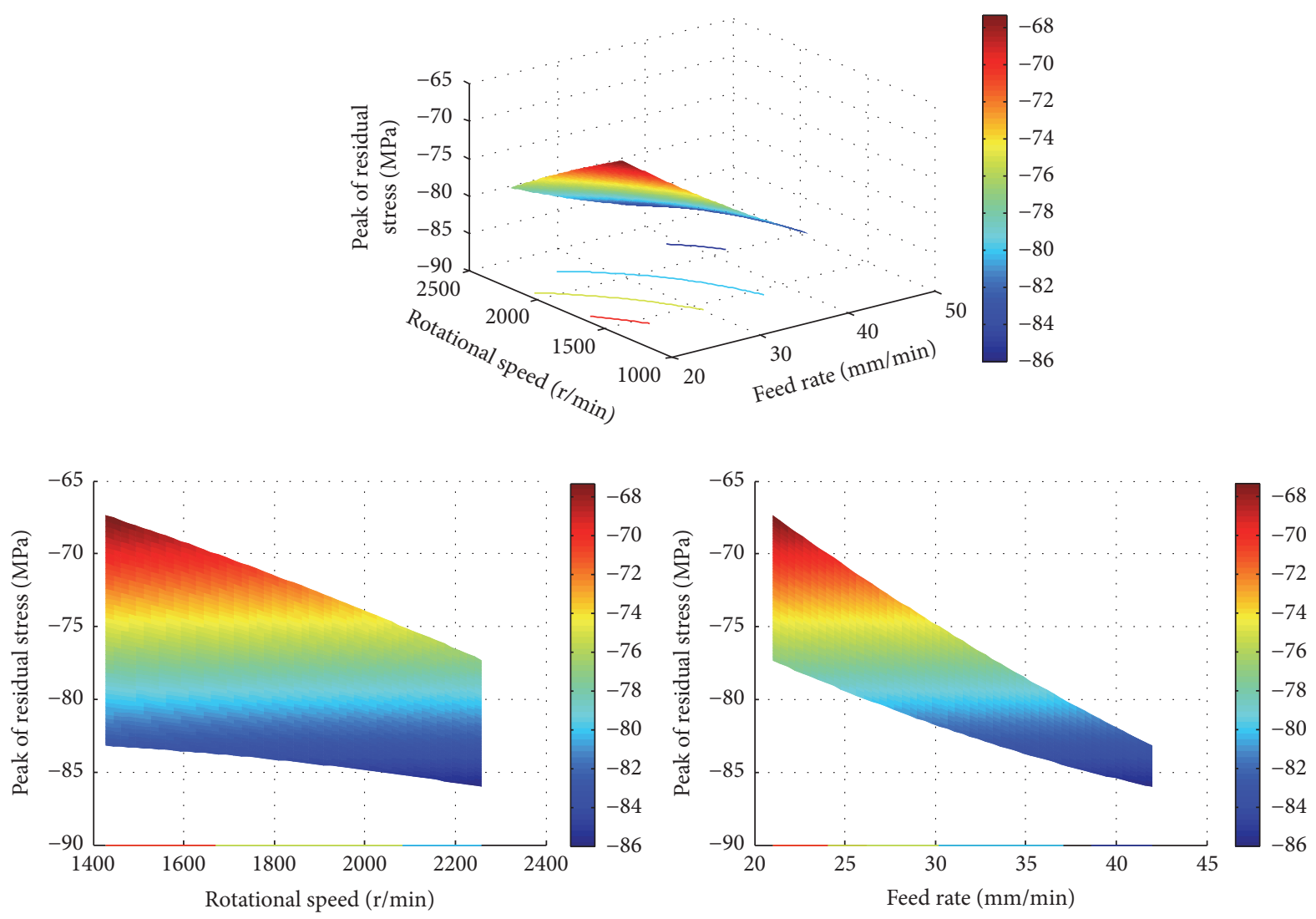

(b) Pitch

Figure 18: Continued. 


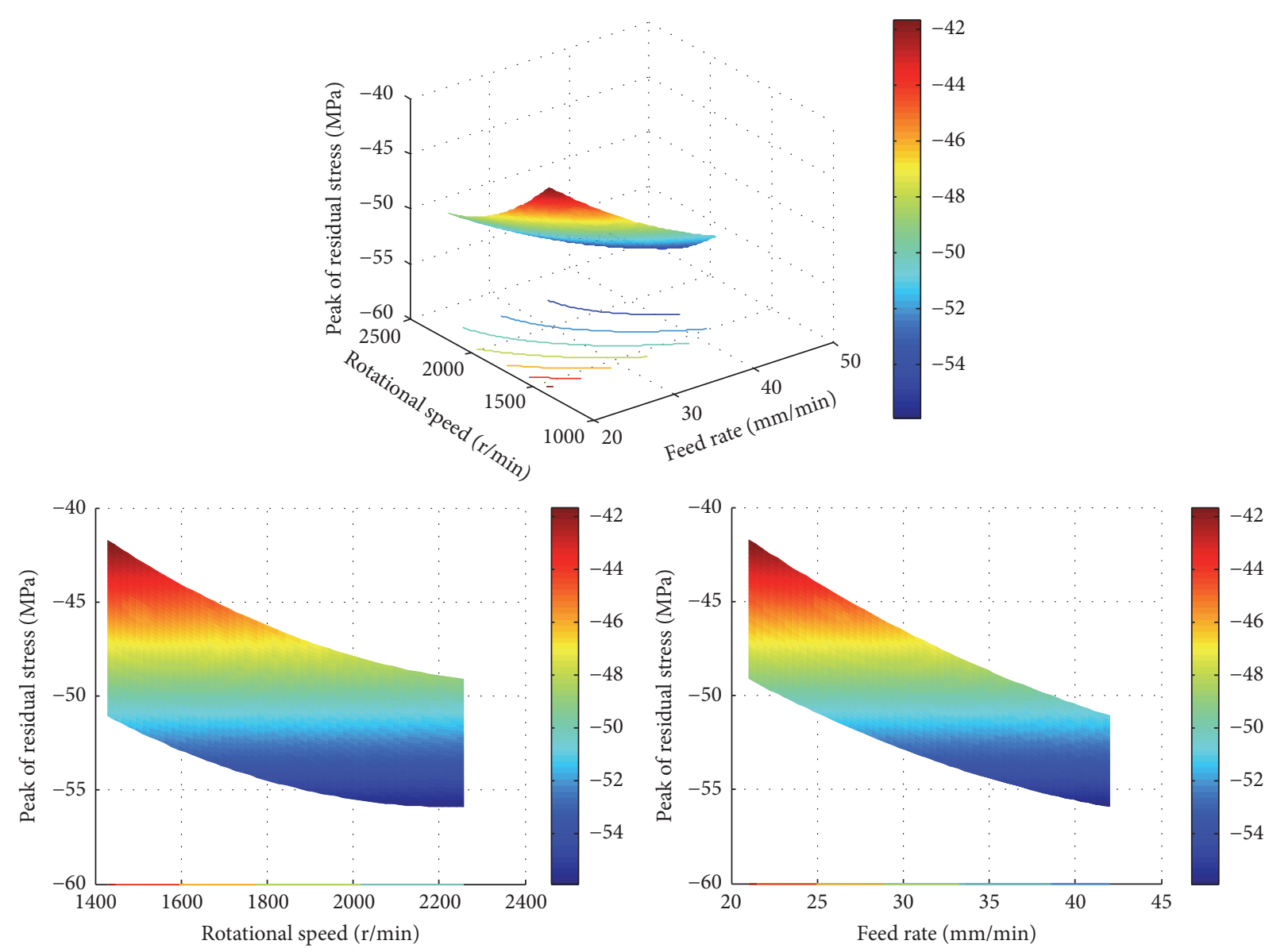

(c) Addendum

FIGURE 18: Corresponding surfaces as functions of the rotational speed and feed rate for the residual stress value of different locations on the tooth profile.

TABLE 3: Results of the depth prediction model for the residual compressive stress layer.

\begin{tabular}{|c|c|c|c|c|c|c|}
\hline & Source of variance & Sum of square & Degree of freedom & Complex correlation coefficient & $F$ value & $F_{0.05}$ \\
\hline \multirow{3}{*}{ Dedendum } & SSR & 0.0328 & 5 & \multirow{3}{*}{0.9676} & \multirow{3}{*}{59.7443} & \multirow{3}{*}{3.33} \\
\hline & SSE & 0.0011 & 10 & & & \\
\hline & SST & 0.0339 & 15 & & & \\
\hline \multirow{3}{*}{ Pitch } & SSR & 0.0082 & 5 & \multirow{3}{*}{0.8825} & \multirow{3}{*}{15.0195} & \multirow{3}{*}{3.33} \\
\hline & SSE & 0.0011 & 10 & & & \\
\hline & SST & 0.0093 & 15 & & & \\
\hline \multirow{3}{*}{ Addendum } & SSR & 0.0088 & 5 & \multirow{3}{*}{0.9321} & \multirow{3}{*}{27.4451} & \multirow{3}{*}{3.33} \\
\hline & SSE & 0.0006 & 10 & & & \\
\hline & SST & 0.0094 & 15 & & & \\
\hline
\end{tabular}

In addition, the confidence level of the three models is greater than $95 \%$, which indicates that the prediction results are accurate. The correlation coefficients $R^{2}$ for the dedendum, pitch, and addendum are $96.76 \%, 88.25 \%$, and $93.21 \%$, respectively, which indicate that the fitting results are accurate. Thus, a strong correlation between the predicted values and the measured values is observed.

According to the residual stress layer depth model, the residual stress layer depth in the tooth profile with the rotational speed and spline feed rate is shown in Figure 19.
The response surface in Figure 19 shows that the combined effect of the roll-beating speed and spline feed rate has a significant effect on the residual compressive stress layer depth. When the rotational speed is constant, the depth of the residual compressive stress layer rapidly increases with an increase in the feed rate, and the growth rate gradually increases. When the spline feed rate is constant, the depth of the residual stress layer exhibits a decreasing trend but the rate of the descent gradually decreases (the top part is slightly different). The residual compressive stress depth layer is the 

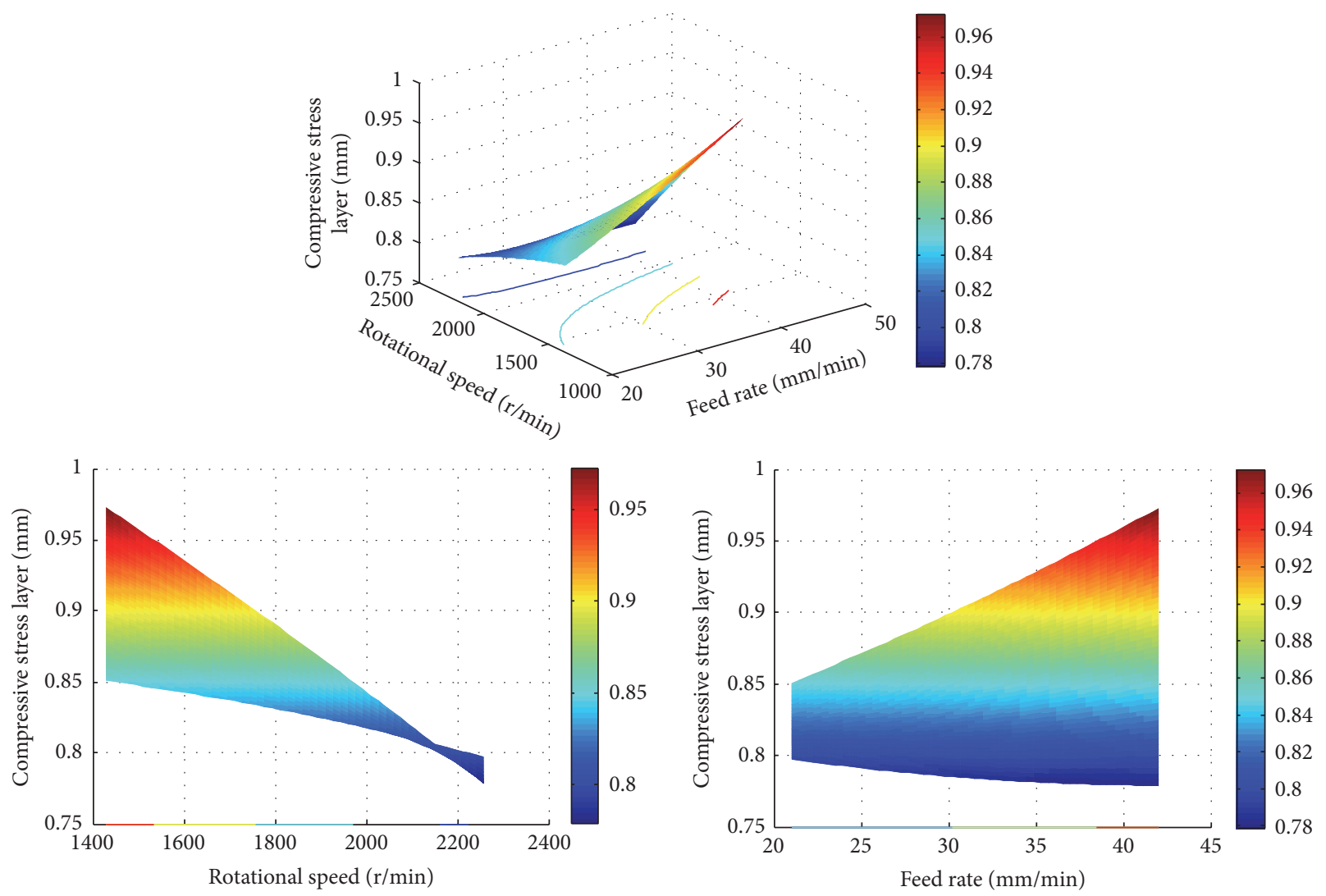

(a) Dedendum
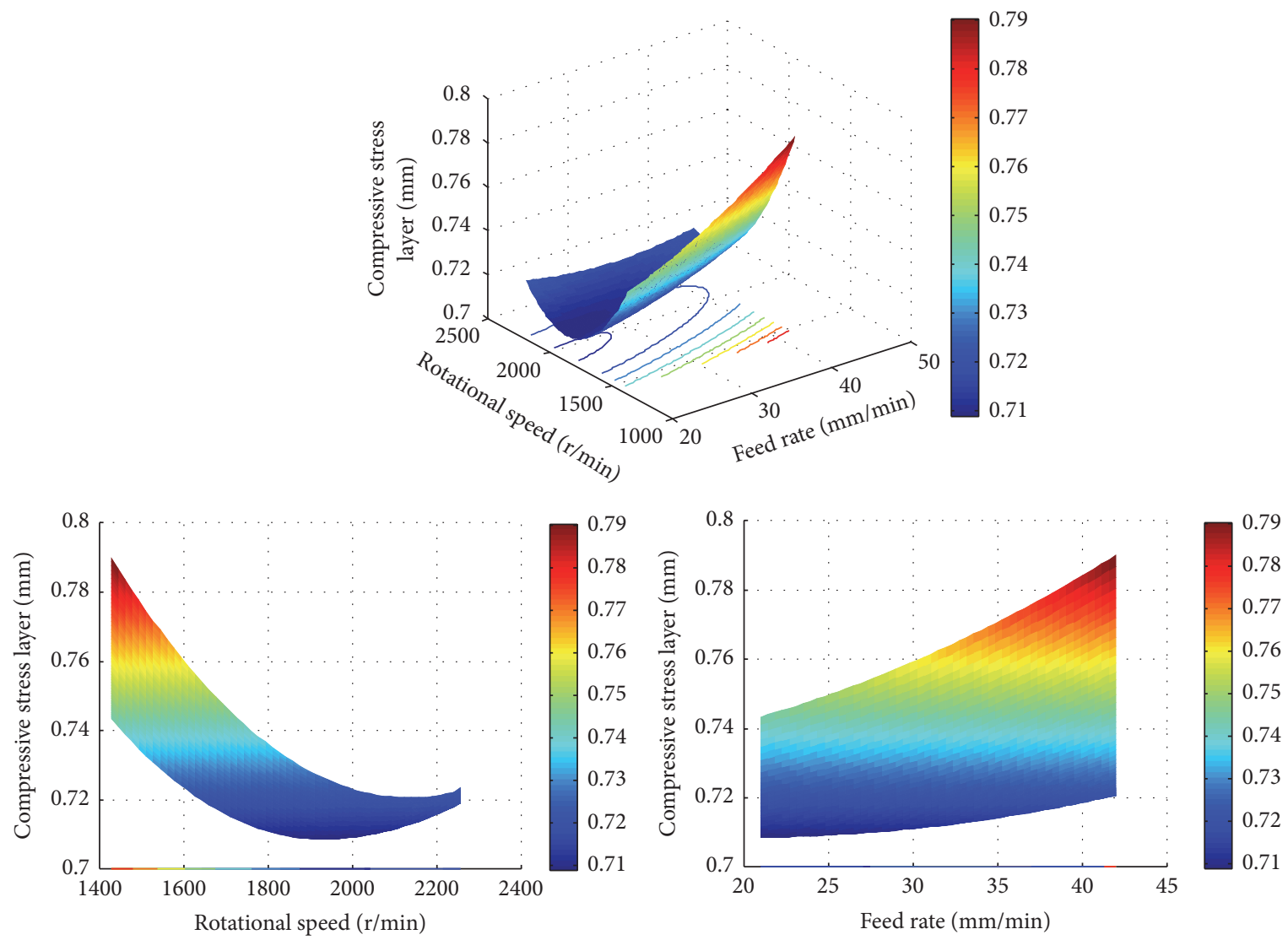

(b) Pitch

Figure 19: Continued. 

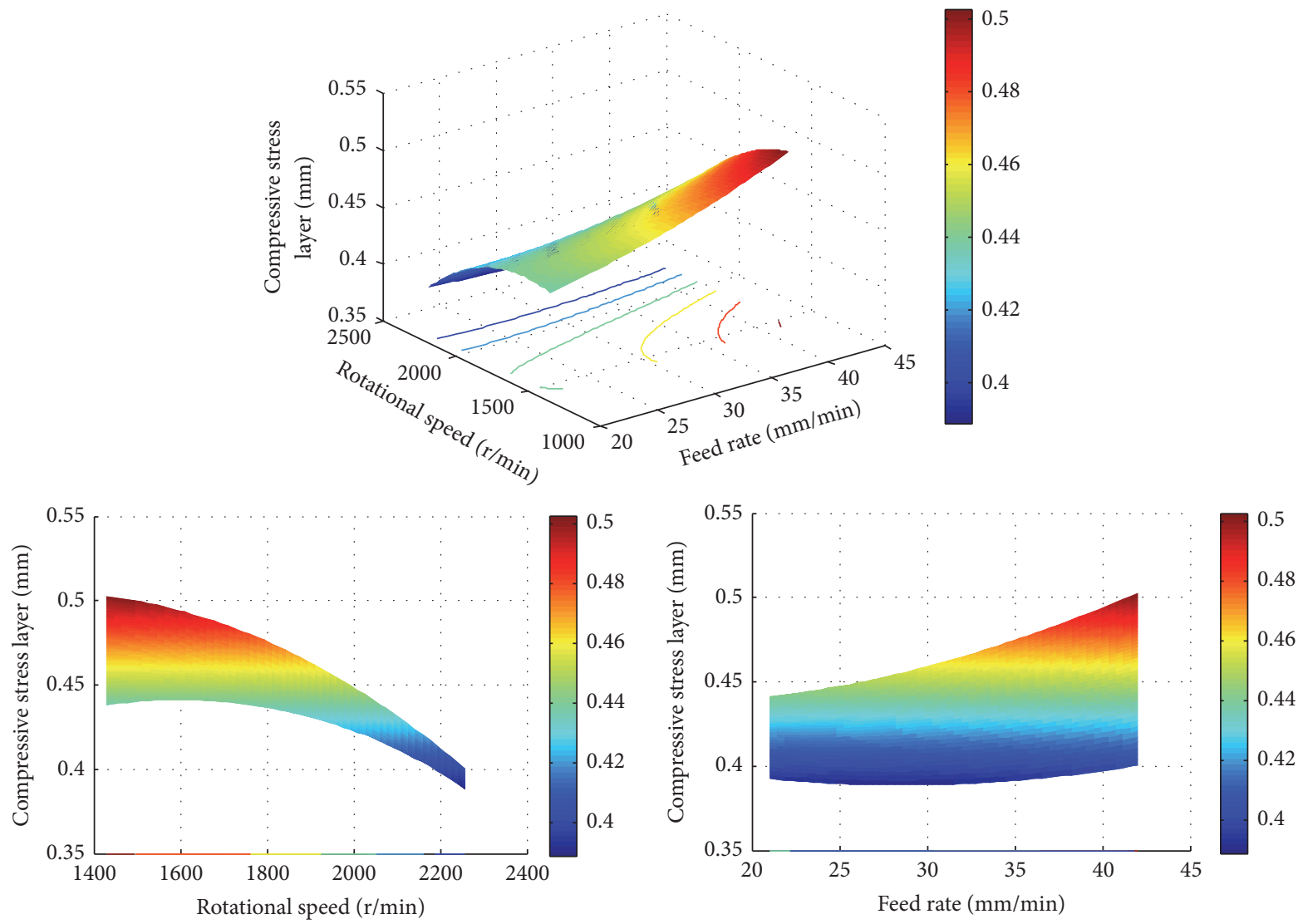

(c) Addendum

FIGURE 19: Response surface of the influence of the rotational speed and feed rate on the residual stress layer depth at different positions of the tooth profile.

same as the residual compressive stress depth layer in the experimental section in terms of the curve trends.

In the cold roll-beating forming process, an increase in the spline feed rate not only can increase the residual stress peak and the residual compressive stress layer depth but also can cause an increase in the contact force of the rolling wheel and the spline and system vibrations. As a result, the spline surface quality decreased, and the excessive increase in the residual stress peak value and the residual compressive stress depth layer caused machining deformation of the workpiece. However, an overly small feed rate will affect the processing efficiency. Therefore, the processing conditions should be appropriate with the increased feed rate but the increase should not be excessive. Increasing the roll-beating rotational speed can also increase the peak value of the residual stress of the spline surface but reduces the contact force between the rolling wheel and the spline and the depth of the residual compressive stress layer; therefore, a better spline surface quality can be obtained.

\section{Contrast Analysis of the Predicted and Experimental Results of the Established Model}

The residual stress peak values and residual compressive stress layer depth were experimentally obtained, and a model for the comparative analysis for a roll-beating rotational speed of 2,258 r/min and spline feed rates of 21, 28, 35, and $42 \mathrm{~mm} / \mathrm{min}$ was established. The comparative analysis results of the residual stress peak values and residual stress layer depth are shown in Figures 20 and 21.

Figure 20 shows that the curve change tendency of the predicted results for the residual stress peak value at different spline feed rates is consistent with the experimental results. According to the calculation results, the maximum relative error of the residual stress peak value between the predicted results and the experimental results in the dedendum is $2.38 \%$. The maximum relative error of the residual stress peak value between the predicted results and the experimental results in the dedendum is 3.3\%. The maximum relative error of the residual stress peak value between the predicted results and the experimental results in the dedendum is $3.14 \%$.

Figure 21 shows that the curve change tendency of the predicted results for the residual stress peak value at different spline feed rates is consistent with the experimental results. According to the calculation results, the maximum relative error of the residual compressive stress layer depth between the predicted results and the experimental results in the dedendum is $6.5 \%$. The maximum relative error of the residual compressive stress layer depth between the predicted results and the experimental results in the pitch is $6.1 \%$. The maximum relative error of the residual compressive stress 


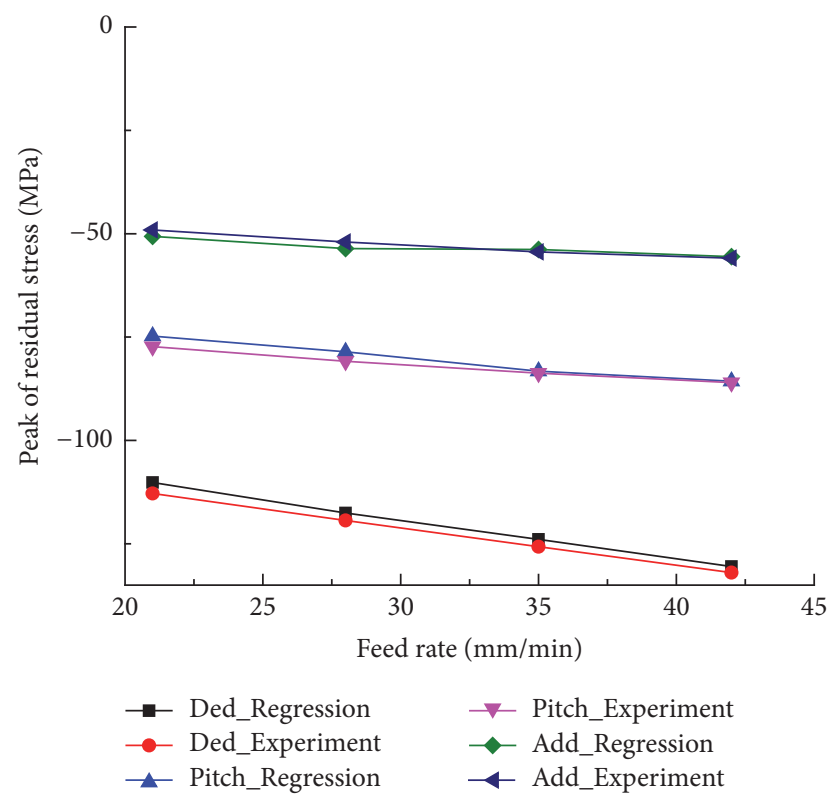

FIGURE 20: Contrast analysis of residual compressive stresses at different positions of the tooth profile.

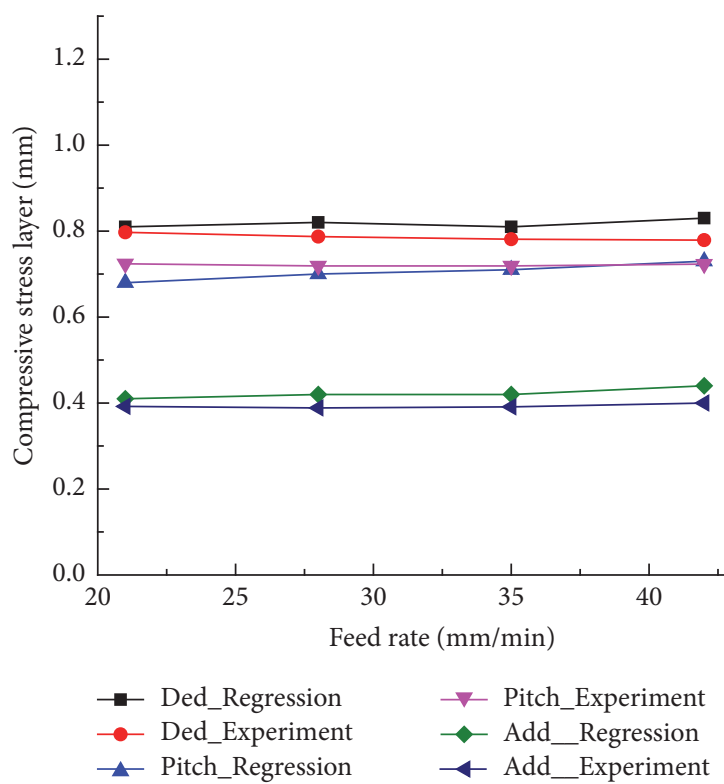

FIGURE 21: Comparative analysis for the compressive residual stress layer at different locations on the tooth profile.

layer depth between the predicted results and the experimental results in the addendum is $10 \%$.

This analysis indicates that the residual stress peak value and the residual compressive stress layer depth model can be employed to control the residual stress and optimize the parameters of the cold roll-beating process.

\section{Conclusions}

The residual stress distribution at the surface of the spline tooth profile was measured for cold roll-beating, the measurement data were analyzed, and the influence of different cold roll-beating parameters on the spatial distribution of the residual stress in different parts of the spline tooth profile was clarified. The main conclusions are as follows.

(1) Cold roll-beating in the spline tooth profile surface causes the formation of residual compressive stress, the residual compressive stress on the spline tooth profile surface is small, the residual compressive stress increases with an increase in the surface layer depth, and the maximum residual compressive stress is attained when the layer depth attains a certain depth. As the depth of the layer increases, the residual compressive stress decreases. When the depth of the spline tooth profile pitch reaches a certain position $(0.68-0.98 \mathrm{~mm})$, the residual compressive stress of the spline tooth profile is 0 , and the residual tensile stress is formed with an increase in the depth of the layer.

(2) The residual compressive stress at the dedendum is higher than the residual compressive stress at the pitch and the addendum, and the smallest residual compressive stress is attained at the addendum.

(3) Increases in the spline feed rate and rotational speed can cause an increase in the residual compressive stress peak value of the tooth surface profile of the cold roll-beating spline shaft. A significant increase in the range of the peak value of the residual compressive stress was observed at the dedendum, and the peak value of the residual compressive stress at the pitch and the addendum did not significantly increase. The peak value of the residual compressive stress at the pitch ranges from $67.4 \mathrm{MPa}$ to $80.8 \mathrm{MPa}$.

(4) The depth of the residual compressive stress layer at the dedendum is deeper than the residual compressive stress layer at the pitch, and the depth of the residual compressive stress layer at the addendum is minimal. The increase of the rotational speed of the cold roll-beating decreases the depth of the residual compressive stress layer at the addendum, and the depth of the residual compressive stress layer at the pitch and the addendum slightly decreases. An increase in the spline feed rate will increase the residual compressive stress layer depth.

(5) In this paper, the second-order regression surface model of the residual stress distribution of cold roll-beating forming is established with a high degree of credibility due to the maximum relative error of the peak of the residual compressive stress of $3.3 \%$, and the maximum relative error of residual compressive stress layer depth is $6.1 \%$ at the pitch. The residual stress distribution and the residual compressive stress layer depth of the superficial spline profile can be predicted for different cold roll-beating parameters. The surface performance of the spline of cold roll-beating forming should be improved, and the forming process parameters should be determined according to the required residual stress state.

\section{Conflicts of Interest}

The authors declare that they have no conflicts of interest.

\section{Acknowledgments}

The authors are grateful for the financial support received from the National Natural Science Foundation of China (51475146, 51475366, and 51075124). 


\section{References}

[1] L. Del Llano-Vizcaya, C. Rubio-Gonzalez, G. Mesmacque, and A. Banderas-Hernández, "Stress relief effect on fatigue and relaxation of compression springs," Materials and Design, vol. 28, no. 4, pp. 1130-1134, 2007.

[2] T. Furumoto, T. Ueda, M. S. Abdul Aziz, A. Hosokawa, and R. Tanaka, "Study on reduction of residual stress induced during rapid tooling process: Influence of heating conditions on residual stress," Key Engineering Materials, vol. 447, pp. 785-789, 2010.

[3] C. J. Lammi and D. A. Lados, "Effects of residual stresses on fatigue crack growth behavior of structural materials: Analytical corrections," International Journal of Fatigue, vol. 33, no. 7, pp. 858-867, 2011.

[4] F. Cui K, X. Dong D, and X. Wang Q, “Experimental analysis of dynamic mechanical properties of 20 quenched and tempered steel for cold roll-beating," Materials Research Innovations, vol. 19, no. S1, pp. 56-61, 2015.

[5] H. Mizutani and M. Wakabayashi, "Influence of cutting edge shape on residual stresses of cut surface," Journal of Advanced Mechanical Design, Systems and Manufacturing, vol. 4, no. 6, pp. 1201-1209, 2010.

[6] K. T. Cui, Finite Element Analysis and Elastic-Plasticity Correction of Rolling Splines, University of Science and Technology, Luoyang, China, 2006.

[7] F. K. Cui, Study of High-Speed Precise Forming with Cold RollBeating Technique, University of Technology, Xian, China, 2007.

[8] J. Quan, F. Cui, J. Yang, H. Xu, and Y. Xue, "Numerical simulation of involute spline shaft's cold-rolling forming based on ANSYS/LS-DYNA," Zhongguo Jixie Gongcheng/China Mechanical Engineering, vol. 19, no. 4, pp. 419-427, 2008.

[9] Cui. K. F., Y. Li, W. Y. Zhou et al., "Roller modeling for ivolute spline and its amendment," Journal of Nanjing University of Aeronutics Astronautics, vol. 37, no. S1, pp. 99-101, 2005.

[10] F. Cui, Y. Li, Y. Zhou, J. Yang, Z. Zhou, and C. Li, "CAD system of roller for involute spline and simulation of grinding process," Jixie Gongcheng Xuebao/Chinese Journal of Mechanical Engineering, vol. 41, no. 12, pp. 210-215, 2005.

[11] X. J. Yang, K. F. Cui, Q. X. Wang et al., "Design theory and experimental amends of involute spline roller," China Mechanical Engineering, vol. 24, pp. 8-11, 2004.

[12] Y. Li, Y. X. Li, M. S. Yang et al., "Analyzing the thermal mechanical coupling of $40 \mathrm{Cr}$ cold roll beating forming process based on the Johnson-Cook dynamic constitutive equation," International Journal of Heat and Technology, vol. 33, no. 3, pp. 51-58, 2015.

[13] F. Cui, X. Wang, F. Zhang, H. Xu, J. Quan, and Y. Li, "Metal flowing of involute spline cold roll-beating forming," Chinese Journal of Mechanical Engineering (English Edition), vol. 26, no. 5, pp. 1056-1062, 2013.

[14] F. K. Cui, K. G. Xie, Y. F. Xie, X. Q. Wang, W. J. Zhu, and Y. Li, "Analysis of coupled thermal-mechanical mechanism based on work hardening phenomenon in high-speed cold roll-beating," Materials Research Innovations, vol. 19, no. S5, pp. 1212-1218, 2015.

[15] L. Zhang, M. Yang S, Y. Li et al., "Analytic metriocl and its modification for cletormation force of high-speed cold roll-beating forming," Journal of Plasticity Engineering, vol. 18, no. 5, pp. 1-7, 2011.

[16] F. Valiorgue, J. Rech, H. Hamdi, P. Gilles, and J. M. Bergheau, " $3 \mathrm{D}$ modeling of residual stresses induced in finish turning of an
AISI304L stainless steel," International Journal of Machine Tools and Manufacture, vol. 53, no. 1, pp. 77-90, 2012.

[17] V. G. Navas, O. Gonzalo, and I. Bengoetxea, "Effect of cutting parameters in the surface residual stresses generated by turning in AISI 4340 steel," International Journal of Machine Tools and Manufacture, vol. 61, pp. 48-57, 2012.

[18] H. Jiang, U. Domenico, and S. Rajiv, "Investigation of cutting conditions and cutting edge preparations for enhanced compressive subsurface residual stress in the hard turning of bearing steel," Journal of Materials Processing Technology, vol. 171, no. 2, pp. 180-187, 2006.

[19] Y. Sun, H. Liu, and Z. Lu, "Finite element simulation and experimental research of residual stresses in the cutting based on the coupled thermo-mechanical model," Jixie Gongcheng Xuebao/ Journal of Mechanical Engineering, vol. 47, no. 1, pp. 187-193, 2011.

[20] E. Capello, "Residual stresses in turning: Part II. Influence of the machined material," Journal of Materials Processing Technology, vol. 180, no. 1-3, pp. 271-278, 2006.

[21] D. Ulutan, B. Erdem Alaca, and I. Lazoglu, "Analytical modelling of residual stresses in machining," Journal of Materials Processing Technology, vol. 183, no. 1, pp. 77-87, 2007.

[22] I. Lazoglu, D. Ulutan, B. E. Alaca, S. Engin, and B. Kaftanoglu, "An enhanced analytical model for residual stress prediction in machining," CIRP Annals - Manufacturing Technology, vol. 57, no. 1, pp. 81-84, 2008.

[23] W. Guo, "Three-dimensional analyses of plastic constraint for through-thickness cracked bodies," Engineering Fracture Mechanics, vol. 62, no. 4-5, pp. 383-407, 1999.

[24] H. Ding, Research on Residual Stress of Ultra-Precise Cutting Based on Multi-Scsle Simulation, Institute of Technology, Harbin, China, 2007.

[25] M. B. Prime, "Cross-sectional mapping of residual stresses by measuring the surface contour after a cut," Journal of Engineering Materials and Technology, vol. 123, no. 4, pp. 162-168, 2001.

[26] P. Pagliaro, M. B. Prime, J. S. Robinson et al., "Measuring Inaccessible Residual Stresses Using Multiple Methods and Superposition," Experimental Mechanics, vol. 51, no. 7, pp. 11231134, 2011.

[27] C. Liu and X. Yi, "Residual stress measurement on AA6061-T6 aluminum alloy friction stir butt welds using contour method," Materials and Design, vol. 46, no. 4, pp. 366-371, 2013. 


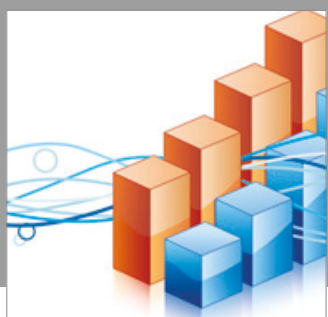

Advances in

Operations Research

vatersals

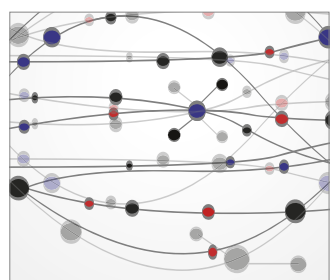

\section{The Scientific} World Journal
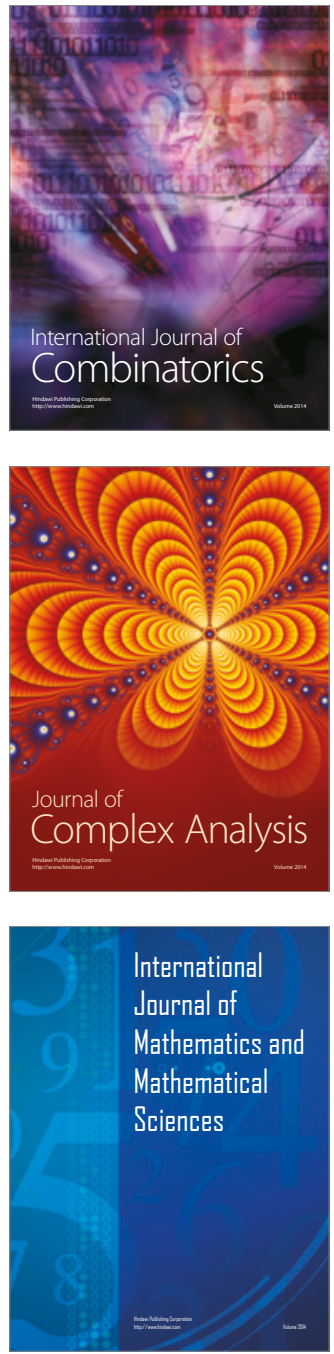
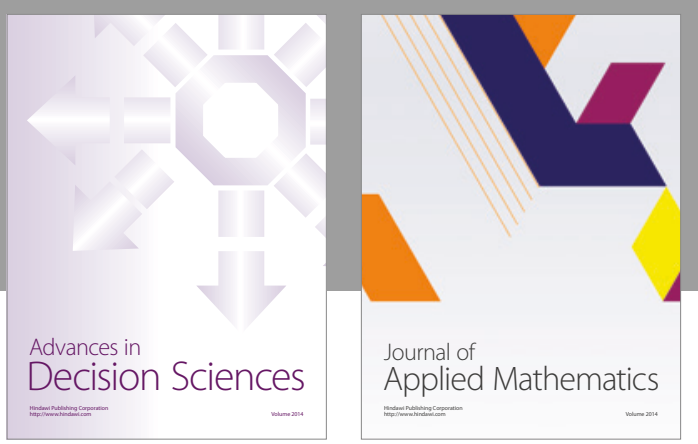

Algebra

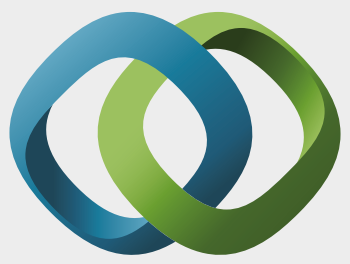

\section{Hindawi}

Submit your manuscripts at

https://www.hindawi.com
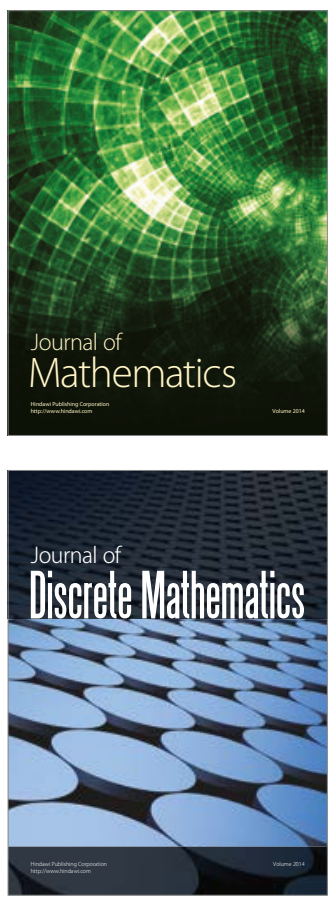

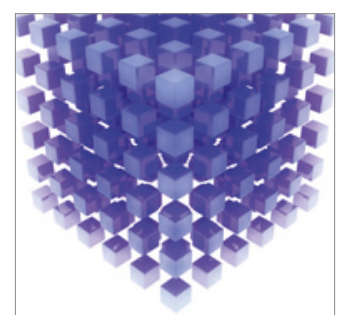

Mathematical Problems in Engineering
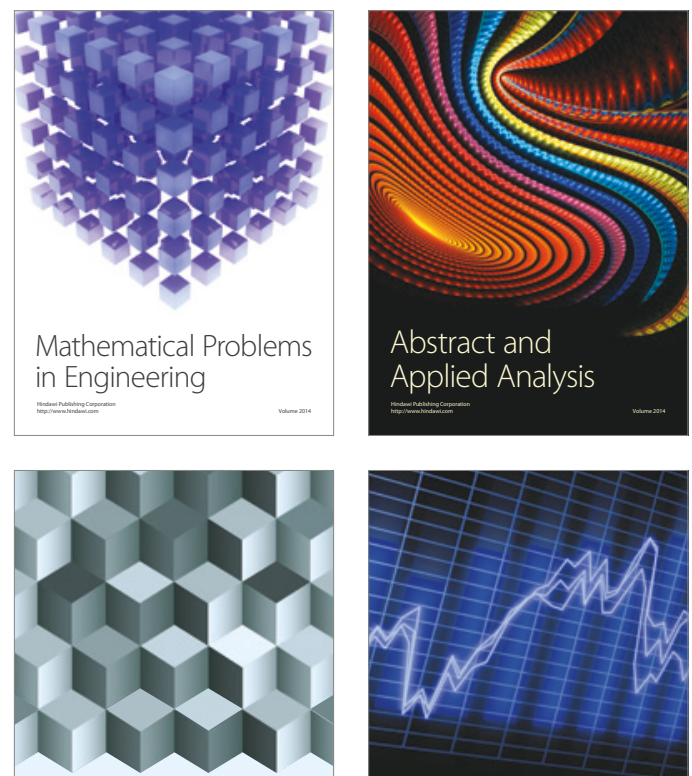

Journal of

Function Spaces

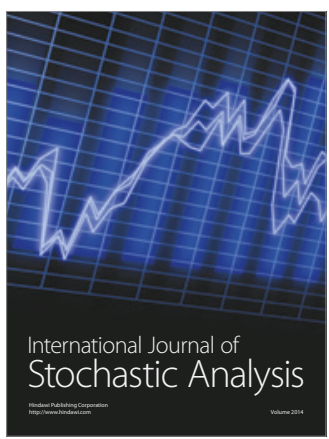

Probability and Statistics
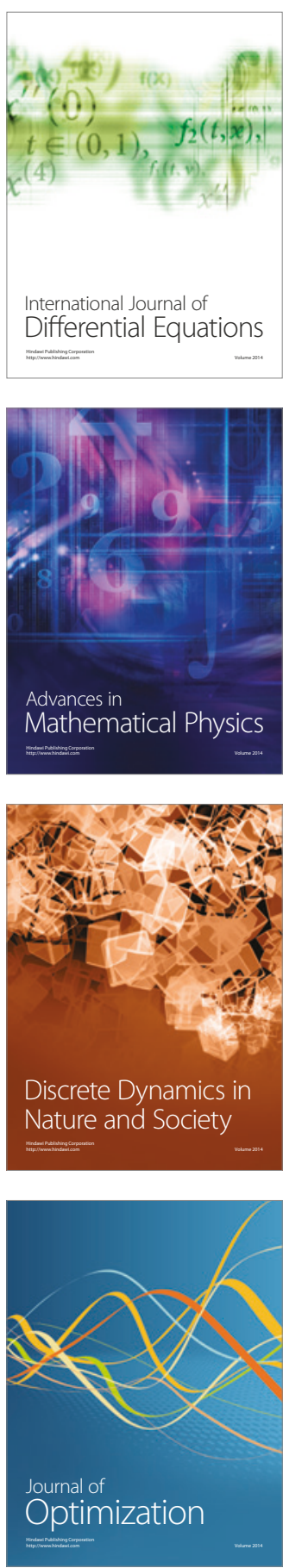